The Free Internet Journal

for Organic Chemistry
Review

Arkivoc 2020, part $i, 437-471$

\title{
Hexahydropyrrolo[2,3-b]indole alkaloids of biological relevance: proposed biosynthesis and synthetic approaches
}

\author{
Avishek Roy, ${ }^{a}$ Arindam Maity, ${ }^{a}$ Saina Shaheeda MK, ${ }^{a}$ Rahul Giri, ${ }^{a}$ and Alakesh Bisai*a,b \\ ${ }^{a}$ Department of Chemistry, Indian Institute of Science Education and Research Bhopal, Bhauri, Bhopal - \\ 462066, Madhya Pradesh, India \\ ${ }^{b}$ Department of Chemical Sciences, Indian Institute of Science Education and Research Kolkata, Mohanpur, \\ Nadia - 741 246, West Bengal, India \\ Email: alakesh@iiserkol.ac.in, alakeshb@gmail.com
}

Received 07-20-2020

Accepted 09-29-2020

Published on line $10-22-2020$

\section{Abstract}

The hexahydropyrrolo[2,3-b]indole alkaloids represent a diverse family of structurally complex tryptamine derived alkaloids isolated from a widespread series of natural sources. A hexahydropyrrolo[2,3-b]indole ring having a carbon substituent at $\mathrm{C}-3 a$ is the defining structural feature of a diverse collection of natural products. The structural complexity of the hexahydropyrrolo[2,3-b]indole alkaloids makes them a particularly elusive and at the same time, appealing target for total synthetic effort. In this review article, we discuss on the biosynthetic proposal as well as key efforts on the total syntheses of naturally occurring complex hexahydropyrrolo[2,3-b] indole alkaloids.

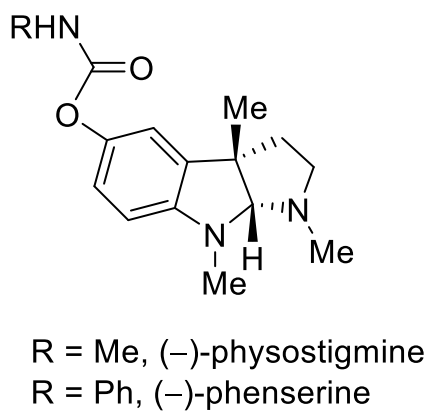

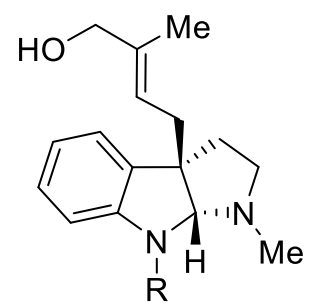

$\mathrm{R}=\mathrm{H},(-)$-pseudophrynaminol

$\mathrm{R}=\mathrm{Me},(-)$-pseudophrynamine $272 \mathrm{~A}$

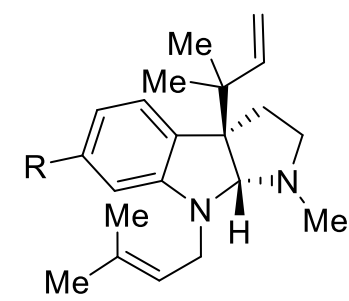

$\mathrm{R}=\mathrm{Br},(-)$-flustramine $\mathrm{A}$

$\mathrm{R}=\mathrm{H},(-)$-debromoflustramine $\mathrm{A}$

Keywords: Hexahydropyrrolo[2,3-b]indole alkaloids, natural products, total synthesis, biological activities 


\section{Table of Contents}

1. Introduction

2. Representatives of Hexahydropyrrolo[2,3-b]indole Alkaloids

3. Biological Profiles of Hexahydropyrrolo[2,3-b]indole Alkaloids

4. Proposed Biosynthesis of Hexahydropyrrolo[2,3- $b$ ]indole Alkaloids

4.1 Biosynthesis of C-3 methylated hexahydropyrrolo[2,3-b]indole alkaloids

4.2 Biosynthesis of C-3 prenylated hexahydropyrrolo[2,3-b]indole alkaloids

5. Synthetic Approaches to the Hexahydropyrrolo[2,3-b]indole Alkaloids

5.1 Non-stereocontrolled synthesis of hexahydropyrrolo[2,3-b]indole alkaloids

5.2 Stereocontrolled synthesis of hexahydropyrrolo[2,3-b]indole alkaloids

6. Conclusions

7. Acknowledgements

References and Notes

Author's Information

\section{Introduction}

Nitrogen containing heterocycles are omnipresent in bioactive compound of both natural and synthetic origin. In this regard, the hexahydropyrrolo[2,3-b]indole alkaloids are a subset of tryptamine derived tricyclic structures (also known as cyclotryptamine alkaloids) with an all-carbon stereogenic center at the pseudobenzylic position. These cyclotryptamine alkaloids are important building blocks in the total synthesis of natural products, as well as for the development of new drugs. ${ }^{1}$ Architecturally intriguing C-3 alkylated hexahydropyrrolo[2,3-b] indole alkaloids (1a-r, Figures 1 and 2) are an important class of indole alkaloids which are found in an array of natural products. ${ }^{1}$ A subset of methylated, prenylated and reverse-prenylated hexahydropyrrolo[2,3-b]indole natural products exhibit a broad spectrum of biological activities. ${ }^{2}$ The characteristic molecular architecture and promising medicinal value has prompted the development of a number of methods to access such motifs, with numerous studies particularly in the area of pyrrolidinoindoline syntheses.

\section{Representatives of Hexahydropyrrolo[2,3-b]indole Alkaloids}

The cyclic hexahydropyrrolo[2,3-b]indole alkaloids of type 1a-r (Figures 1 and 2) is the fundamental building block of cyclotryptamine alkaloids. One of the congener of this family, physostigmine (1d), isolated from the African Calabar bean seeds, ${ }^{3,4}$ of Physostigma venenosum. ${ }^{5}$ This is the oldest known acetylcholinesterase (AChE) inhibitor. ${ }^{6}$ Physostigmine (1d) drew much of attention from medicinal and synthetic groups due to its unique structural feature and potent biological activity. ${ }^{7}$ The analogues of naturally occurring hexahydropyrrolo[2,3-b] indole alkaloid $\mathbf{1 d}$, i.e. (-)-eseroline (1) $)$ and (-)-esermethole (1) were synthesized by the hydrolysis of physostigmine (1d) (Figure 1). It is worthwhile to mention that, (-)-eseroline (1b) display potent morphine-like analgesic effects. ${ }^{8}$ 


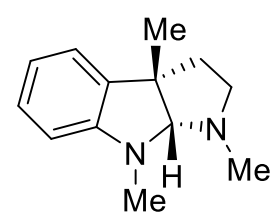

(-)-deoxyeseroline (1a)

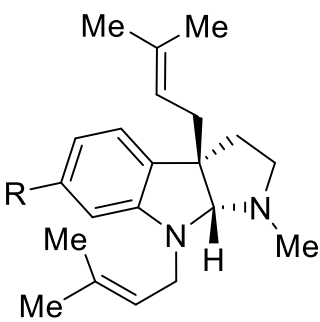

$\mathrm{R}=\mathrm{H},(-)$-debromoflustramine $\mathrm{B}(\mathbf{1 f})$

$\mathrm{R}=\mathrm{Br},(-)$-flustramine $\mathrm{B}(\mathbf{1 g})$

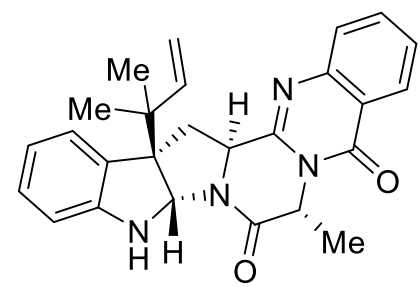

$(-)$-ardeemin (1I)

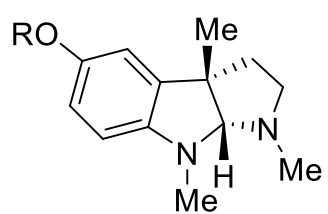

$\mathrm{R}=\mathrm{H},(-)$-eseroline $(\mathbf{1 b})$

$\mathrm{R}=\mathrm{Me},(-)$-esermethole (1c)

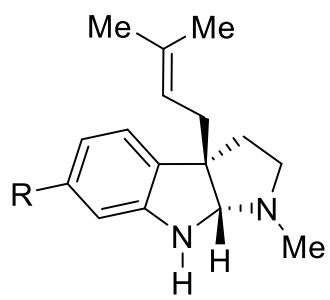

$\mathrm{R}=\mathrm{H},(-)$-debromoflustramine $E(\mathbf{h})$

$\mathrm{R}=\mathrm{Br}$, (-)-flustramine $\mathrm{E}(\mathbf{1 i})$

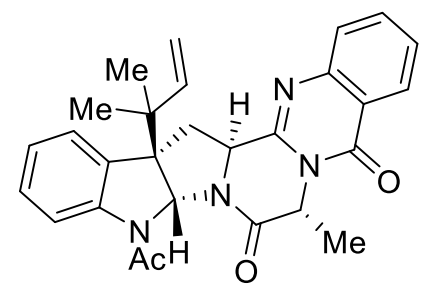

$(-)-5-N$-acetylardeemin $(1 \mathrm{~m})$
RHN

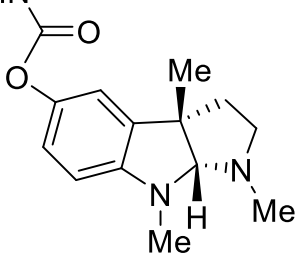

$\mathrm{R}=\mathrm{Me},(-)$-physostigmine (1d)

$\mathrm{R}=\mathrm{Ph},(-)$-phenserine (1e)

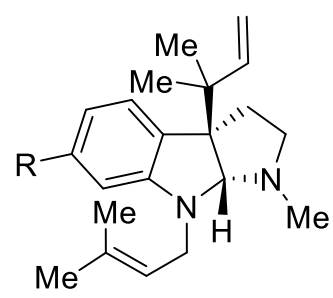

$\mathrm{R}=\mathrm{Br},(-)$-flustramine $\mathrm{A}(\mathbf{1} \mathbf{j})$

$\mathrm{R}=\mathrm{H},(-)$-debromoflustramine $A(\mathbf{1 k})$

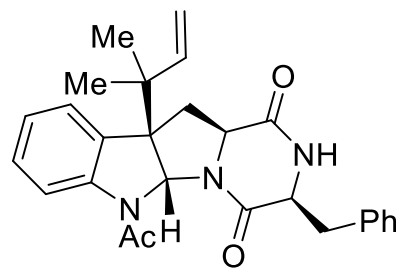

(-)-fructigenine $A(1 \mathbf{n})$

Figure 1. Selected C-3 alkylated hexahydropyrrolo[2,3-b]indole alkaloids (1a-n).

Hexahydropyrrolo[2,3-b]indole alkaloids (Figures 1 and 2) having a prenyl and reverse prenyl moiety adjacent to the pseudobenzylic 3a-site, viz. flustramines (1f-k), ${ }^{9,10}$ ardeemin $(\mathbf{1 l}-\mathbf{m}),{ }^{11,12}$ fructigenine $A(\mathbf{1 n})^{13}$ and pseudophrynamines (10-r), ${ }^{14-17}$ have gained considerable attention owing to their potential biological activities. An array of brominated pyrroloindolines has yielded from marine cheilostome bryozoan Flustra foliacea collected in the North sea. ${ }^{18,19}$ The same species from Canadian waters has yielded five different but closely related indole alkaloids (-)-flustramine $E(\mathbf{1 i})$ and (-)-pseudophrynaminol (10). It is interesting to note that the alkaloids from the Canadian waters showed strong activity against Bacillus subtilis, while those from the North Sea were devoid of such activity. ${ }^{20-22}$ The pioneering work of Carlé and Christophersen led to the isolation of two new metabolites from the Scandinavean bryozoan, Flustra foliacea, which were named (-)flustramines $A(\mathbf{1 j})$ and $B(\mathbf{1 g}) .^{23-24}$ To date, several indole alkaloids and one quinoline have been isolated from Flustra foliacea collected in the North Sea, ${ }^{25-27}$ and from material collected in Canadian waters. ${ }^{28}$ Another type of hexahydropyrazino[2',1'-5,1]pyrrolo[2,3-b]indole ring system bearing a reverse-prenyl group at C10b is a widely distributed structural framework present in a number of biologically active alkaloids such as (-)ardeemin (1), (-)-N-acetylardeemin (1m) and (-)-fructigenine A (1n) have been isolated from a marinederived fungal strain identified as Penicillium fructigenium (Figure 1,2 ). ${ }^{11-13}$ 


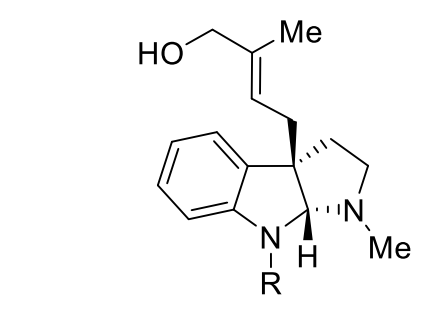

$\mathrm{R}=\mathrm{H},(-)$-pseudophrynaminol (10)

$\mathrm{R}=\mathrm{Me},(-)$-pseudophrynamine $272 \mathrm{~A}(\mathbf{1 p})$

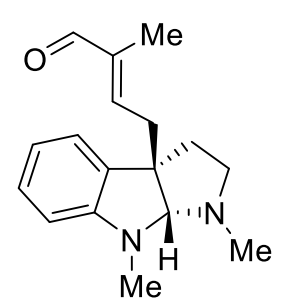

(-)-pseudophrynamine 270 (1q)

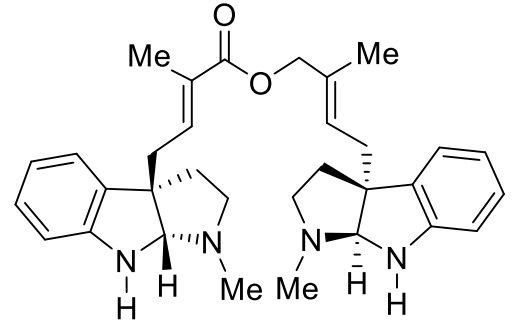

(-)-pseudophrynamine A (1r)

Figure 2. Selected C-3 alkylated hexahydropyrrolo[2,3-b]indole alkaloids (10-r) alkaloids.

Hexahydropyrrolo[2,3-b]indole alkaloids $\mathbf{1 a - k}$ and $\mathbf{1 0 - q}$ possess architecturally interesting structural motifs and share two contiguous stereocenters. Among these two stereocenters, one of them is all-carbon quaternary stereogenic center (Figure 1,2). ${ }^{29-30} \mathrm{~A}$ structural survey of alkaloids (1) reveals a central cis-fused pyrroloindoline core with a quaternary center at C-3a apparently because of the higher level of ring strain in the trans-stereoisomer. The absolute configuration assigned to the naturally occurring (-)debromoflustramine B (1) ), (-)-flustramines $A(\mathbf{1 j})$ and $B(\mathbf{1 g}) .^{31-35}$

\section{Biological Profile of Hexahydropyrrolo[2,3-b]indole Alkaloids}

The history of (-)-physostigmine (1d) and pharmacological effects has been reviewed independently by Holmstedt, ${ }^{36}$ Somani $^{37}$ and Triggle ${ }^{38}$. (-)-Physostigmine (1d) alkaloids isolated from West African perennial shrub Physostigma venenosum. ${ }^{39}$ Initially naturally occurring (-)-physostigmine (1d) was utilized for ophthalmic treatment purposes. ${ }^{40-42}$ The general and dominant pharmacology of physostigmine is due to a short-acting inhibition of the enzymes AChE and butyrylcholinesterase (BuChE). ${ }^{43-45}$

The role of physostigmine (1d) in the central cholinergic nervous system in memory processes was summarized by Deutsch in 1971 and in 1983. ${ }^{46,47}$ Many observations indicating that the role of (-)physostigmine (1d) in the amelioration of the symptoms of Alzheimer's disease. ${ }^{48-50}$ Another new analgesic drug (-)-eseroline (1) can be derived from (-)-physostigmine (1d), after hydrolysis of N-methyl carbamyl group. ${ }^{51}$ Eseroline (1) $)$ as a free base is quite unstable and is easily oxidized, ${ }^{52}$ whereas its salts with acids like salicylic, fumaric, tartaric etc. are stable even in solution in presence of antioxidant agents. In this respect (-)eseroline (1b) resembles (-)-physostigmine (1d) which also possesses antinociceptive activity in various purpose. ${ }^{53-56}$ Unlike the latter compound, however, eseroline (1) is devoid of anticholinesterase activity ${ }^{57}$ and its analgesic effect is not antagonized by atropine. In agreement with the findings of Bartolini ${ }^{58}$ and Ireson $^{59}$ eseroline (1b), a physostigmine (1d) derivative, proved to be a potent analgesic as evidenced by the hot plate test with rats. It has about the same order of potency as morphine. Among these derivatives of physostigmine, the most attractive compound, (-)-phenserine (1e), is a dual AChE and $\beta$-amyloid precursor protein ( $\beta$-APP) inhibitor being developed to treat mild to moderate Alzheimer's disease. Therefore, phenserine may represent an important new catalog of compounds for treatment of $A D$, with the goal of developing potential Alzheimer's pharmacotherapeutics (Figure 1), ${ }^{60,61}$

Flustramines, isolated from the Bryozoa Flusta foliacea, are a family of marine alkaloids with characteristic prenylated or reverse prenylated hexahydropyrrolo[2,3-b]indole backbone. (-)-Flustramine B (1g) possesses skeletal and smooth-muscle relaxant activity and its analogue, (-)-debromoflustramine B (1f) was proven to 
have significant butyrylcholinesterase inhibitory activity and antibacterial activity against vancomycin-resistant Enterococci and methicillin-resistant Staphylococcus aureus. ${ }^{62-64}$ (-)-Pseudophrynaminol (10) was isolated from the skin of the Australian frog Pseudophryne coriacea and emerge as a potent inhibitor of ganglionic and neuromuscular nicotinic receptor-channels (Figure 2). ${ }^{65,66}$

Another class of biologically active indole alkaloid like (-)-ardeemin (1I), (-)- $\mathrm{N}$-acetylardeemin (1m) and (-)-fructigenine $A(\mathbf{1 n})$ display promising bioactivities towards life-threatening diseases. Where as fructigenine A (1n) has growth-inhibitory activity against Avena coleoptile and leukemia L-5178Y cells ${ }^{26}$ and $\mathrm{N}$ acetylardeemin $(\mathbf{1 m})$ is one of the most potent known agents for reversal of multiple drug resistance (MDR), as measured against KBV-1 (vinblastine resistant) tumor cell lines. ${ }^{27}$ Thus, 5- $\mathrm{N}$-acetylardeemin would be termed a naturally occurring MDR reversal agent (Figure 1$).{ }^{67}$

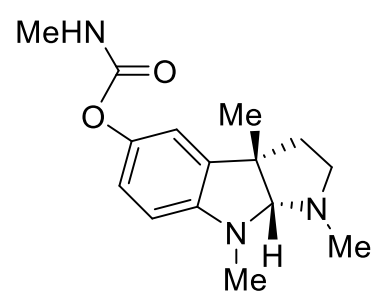

$\mathrm{R}=\mathrm{Me},(-)$-physostigmine (1d)

$\mathrm{R}=\mathrm{Ph},(-)-$ phenserine $(\mathbf{1 e})$

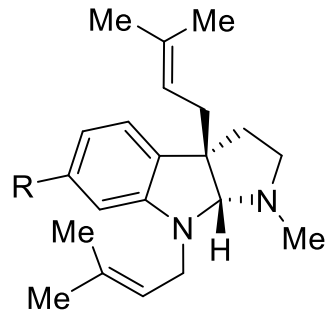

$\mathrm{R}=\mathrm{H},(-)$-debromoflustramine $\mathrm{B}(\mathbf{1 f})$

$\mathrm{R}=\mathrm{Br},(-)$-flustramine $\mathrm{B}(\mathbf{1 g})$

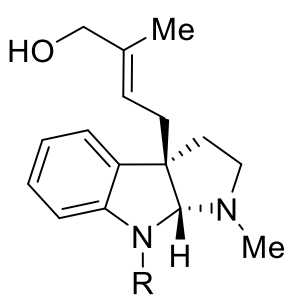

$\mathrm{R}=\mathrm{H},(-)$-pseudophrynaminol (10)

$\mathrm{R}=$ Me, (-)-pseudophrynamine 272A (1p)

Figure 3: Representatives of hexahydropyrrolo[2,3-b]-indole alkaloids.

The biological activities of these compounds have been well studied, the results of which have shown several promising applications, including muscle relaxants, potassium channel-blockers and anti-cancer agents. For this reason, the total synthesis of these natural products has received considerable attention, and has been accomplished by several research groups.

\section{Proposed Biosynthesis of Hexahydropyrrolo[2,3-b]indole Alkaloids}

\subsection{Biosynthesis of C-3 methylated hexahydropyrrolo[2,3-b]indole alkaloids}

Biosynthetically, these alkaloids are believed to be originated from L-tryptophan, which is shown in Scheme 1. A reaction of L-tryptophan (3a) with nature's methylating agent (SAM, S-Adenosyl Methionine, 2a) chemoselectively (a C-C bond formation) to furnish intermediate (3b), which could do iminium cyclization leading to the formation of intermediate (3c). Next, a decarboxylative reaction (probably catalysed by the decarboxylase enzyme) of hexahydropyrrolo[2,3-b]indoline (3c) could afford intermediate $\mathbf{3 d}$ (Scheme 1), which is considered to be the advanced intermediate for all C-3 methylated hexahydropyrrolo[2,3- $b]$ indoline alkaloids. Intermediate $\mathbf{3 d}$ then reacts with methylating agent (SAM, S-Adenosyl Methionine, 2a) could lead to the formation of naturally occurring (-)-deoxyeseroline (1a). Next, deoxyeseroline (1a) could be considered to be the advanced intermediate for all C-3 methylated hexahydropyrrolo[2,3-b]indoline alkaloids, such as (-)eseroline (1) and (-)-esermethole (1c) and (-)-physostigmine (1d). Towards this, an electrophilic oxidation of aromatic ring of (-)-deoxyeseroline (1a) could afford (-)-eseroline (1) $)$, where electrophilic substitution must take place at the $p$-position of $N$-Me group. Eseroline (1b) also could afford other hexahydropyrrolo[2,3$b]$ indole alkaloids such as (-)-physostigmine (1d) and (-)-phenserine (1e). ${ }^{68}$ 


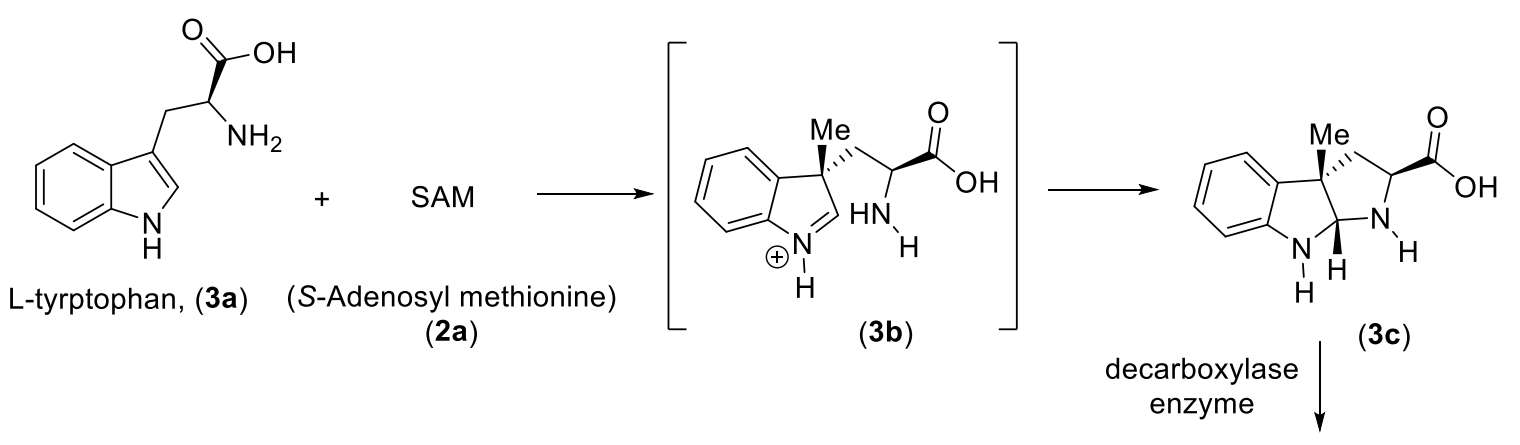

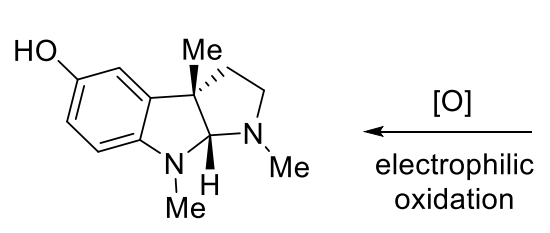
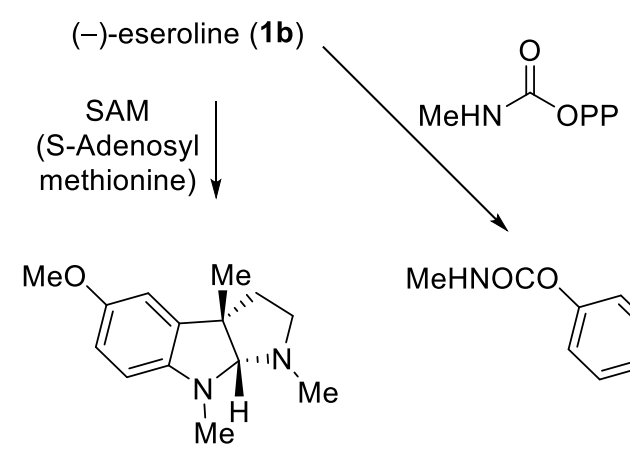

(-)-esermethole (1c)

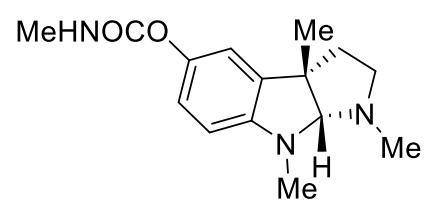

(-)-physostigmine (1d)

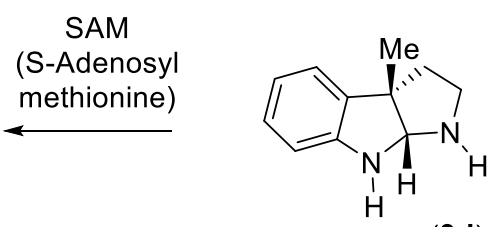

(-)-deoxyeseroline (1a)

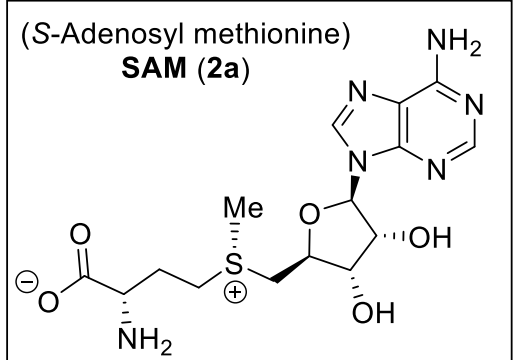

Scheme 1. Proposed biosynthetic proposal to C3-methylated hexahydropyrrolo[2,3-b]-indole alkaloids.

\subsection{Biosynthesis of C-3 prenylated hexahydropyrrolo[2,3-b]indole alkaloids}

Along similar line, biosynthetically, C-3 prenylated hexahydropyrrolo[2,3-b]indoline alkaloids are believed to be originated from L-tryptophan 3a, which is shown in Scheme 2. A reaction of L-tryptophan (3a) with a 3,3dimethylallyl pyrophosphate (DMAPP, 2b) to craft the hexahydropyrrolo[2,3-b]indoline core (4b) via the intermediacy of iminium 4a. ${ }^{20}$ Next, a decarboxylative reaction (probably catalysed by the decarboxylase enzyme) of hexahydropyrrolo[2,3-b]indoline (4b) could afford intermediate $4 \mathbf{c}$ (Scheme 2), which is considered to be the advanced intermediate for all C-3 prenylated hexahydropyrrolo[2,3-b]indoline alkaloids. Intermediate 4c then reacts with methylating agent (SAM, S-Adenosyl Methionine) chemoselectively to furnish (-)-debromoflustramine E (1h). Further methylation using SAM could lead to the formation of $N$ methyl debromoflustramine $E$ (4d). Later, a regioselective allylic oxidation of $N$-methyl debromoflustramine $E$ (4d) could generate (-)-pseudophrynamine 272A (1p), which on further oxidation affords (-)pseudophrynamine 270 (1q). 
<smiles>CC(C)=CCO[Pb]</smiles>

L-tyrptophan, (3a) 3,3-dimethylallyl pyrophosphate, (DMAPP) (2b)

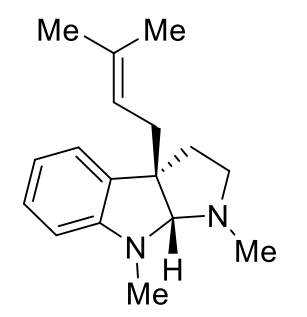

$N$-methyl debromoflustramine $E$ (4d)

\section{SAM (S-Adenosyl} methionine)<smiles>CC(C)=CC[C@@]1(CC(NN)C(=O)O)C=[NH+]c2ccccc21</smiles>

(4a)<smiles>CC(C)=CC[C@]12C[C@@H](C(=O)O)NN1[CH]Nc1ccccc12</smiles>

(4b)

decarboxylase enzyme
[O] $\downarrow \begin{gathered}\text { regioselective } \\ \text { allylic oxidation }\end{gathered}$

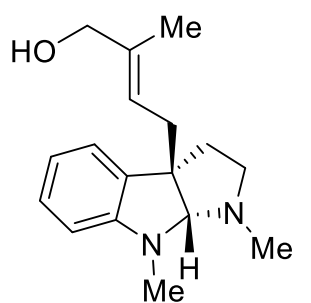

(-)-pseudophrynamine $272 \mathrm{~A}$
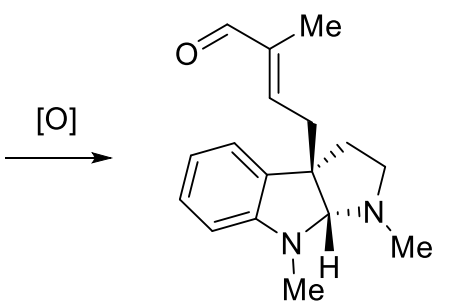

(1p) (-)-pseudophrynamine $270(1 \mathrm{q})$

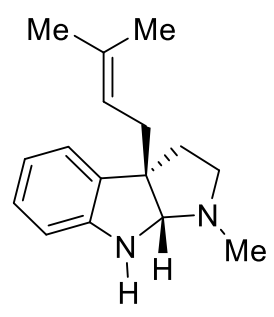

(-)-debromoflustramine $E(1 \mathrm{~h})$

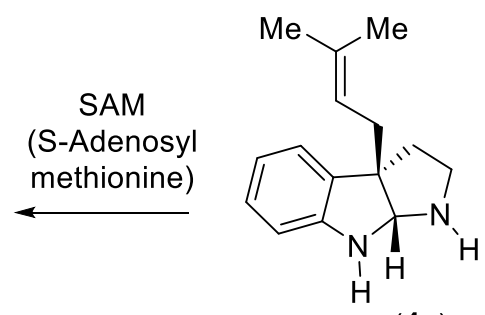

(4c)

Scheme 2. Proposed biosynthetic proposal to C3-prenylated hexahydropyrrolo[2,3-b]-indole alkaloids.

Further, regioselective allylic oxidation of (-)-debromoflustramine $E(\mathbf{1 h})$ could complete the synthesis of (-)-pseudophrynaminol (10). Because of their interesting architecture with a vicinal stereogenic center (out of which one of them is having an all-carbon quaternary stereogenic center), a number of efficient strategies for the construction of such quaternary stereogeniccenters were developed. ${ }^{69-70}$

\section{Synthetic Approaches to the Hexahydropyrrolo[2,3-b]indole Alkaloids}

\subsection{Non-stereocontrolled synthesis of hexahydropyrrolo[2,3-b]indole alkaloids}

The first synthesis of physostigmine was reported by Julian and Pikl in $1935,{ }^{71}$ via a key reductive cyclization of 1,3-dimethyl-5-ethoxyoxindolylethyl-methylamine (5a) to eserethol (1s) (Scheme 3). Resolution of ( \pm )-amine (5a) using (+)-camphorsulphonic acid and (+)-tartaric acid gave (-)-amine base (5a), which was reacted with sodium and ethanol to furnish (-)-eserethole (1s) with excellent yield. Later the transformation of (-)eserethole (1s) to (-)-eseroline (1b) was conducted by gently boiling of (1s) in petroleum ether in presence of anhydrous $\mathrm{AlCl}_{3}$. Polonovski and Nitzberg have disclosed the conversion of (-)-eseroline (1) to (-)- 
physostigmine (1d) by treatment of (-)-eseroline (1) with methyl isocyanate to complete the synthesis of (-)physostigmine (1d) (Scheme 3). ${ }^{72}$<smiles>CCOc1ccc2c(c1)[C@](C)(CCNC)C(=O)N2C</smiles>

$(-)$-amine (5a)

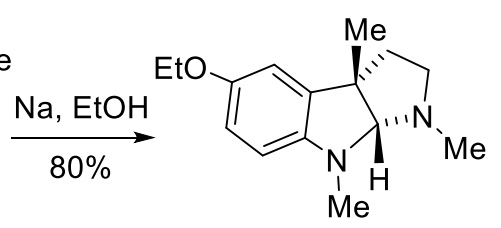

$(-)$-eserethole (1s)

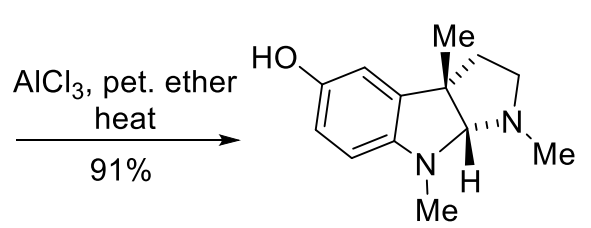

(-)-eseroline (1b)

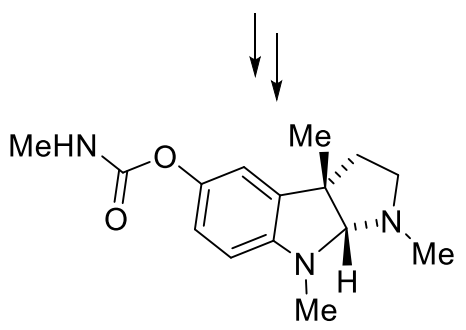

(-)-physostigmine (1d)

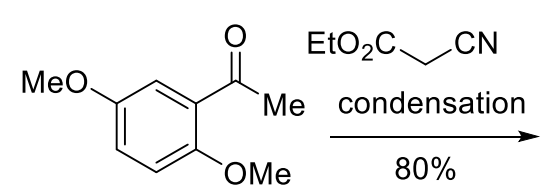

(6a)<smiles>CCOC(C#N)=C(C)c1cc(OC)ccc1OC</smiles>

(6b)

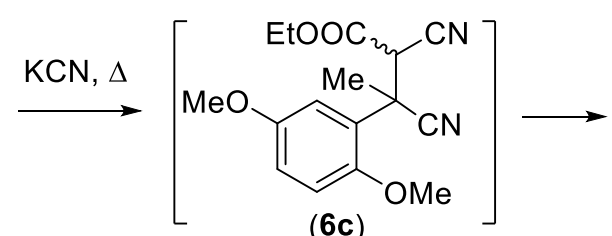

(6c)

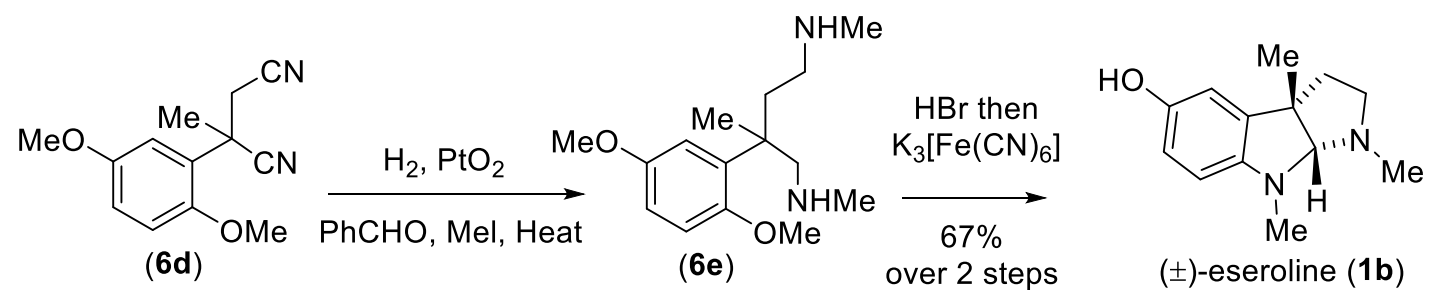

Scheme 3. Total synthesis of eseroline (1b) reported independently by Pikl et al. and Harley-Mason et al.

In 1954, Harley-Mason et. al. ${ }^{73}$ have reported racemic synthesis of ( \pm )-eseroline (1b) from 2,5dimethoxyacetophenone (6a) (Scheme 3). Initially 2,5-dimethoxyacetophenone (6a) was condensed with ethyl cyanoacetate to produced ethyl 1-cyano-2-(2,5-dimethoxyphenyl)crotonate (6b) with $80 \%$ yield. Next, $\mathbf{6 b}$ was converted to 2-(2,5-dimethoxyphenyl)-2-methylbutane-1,4-diamine (6e) via the intermediacy of $\mathbf{6 c}$ and $\mathbf{6 d}$ by reacting with $\mathrm{KCN}$ followed by hydrogenation over $\mathrm{PtO}_{2}$ in presence of $\mathrm{HCl}$ and next $\mathrm{N}, \mathrm{N}$ '-dimethylation using benzyldehyde and $\mathrm{Mel}$ under heating condition. Then demethylation by hydrobromic acid followed by potassium ferricyanide oxidation yielded the product $( \pm$ )-eseroline $(\mathbf{1 b})$ via the intermediate $p$-benzoquinone with $67 \%$ yield over 2 steps (Scheme 3 ).

In 1977, Ikeda group ${ }^{74}$ disclosed the synthesis of ( \pm )-esermethole (1c) via a photochemical route from ethyl 2-cyano-6-methoxy-4-methylquinoline-1(2H)-carboxylate (7a) (Scheme 4). Photolysis of compound 7 a in ethanol in pyrex tube yielded $10 \%$ endo-cyanocycloprop $[b]$ indole $\mathbf{7 b}$. Later, alkaline hydrolysis of $\mathbf{7 b}$ furnished the furo[2,3-b] indole 8 a in $69 \%$ yield following in situ sequential hydrolysis, ring opening, hydrolysis of cyano group and recyclisation step. Finally, $N$-Methylation by methyl iodide followed by reduction using lithium 
aluminum hydride completed the synthesis of $( \pm$ )-esermethole (1c) in $25 \%$ overall yield over 3 steps (Scheme 4).

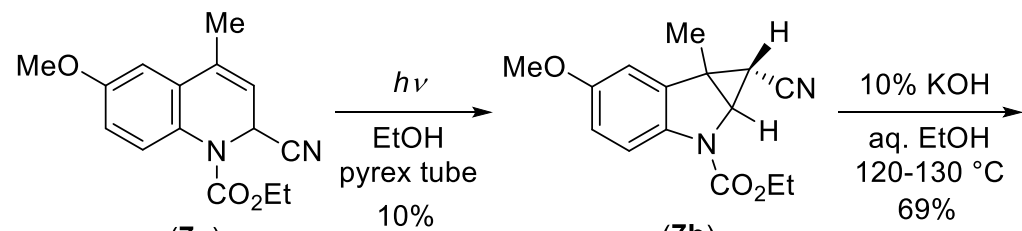

(7a)
$10 \%$

(7b)<smiles>COc1ccc2c(c1)[C@]1(C)OC(=O)C[C@H]1N2</smiles>

(8a)

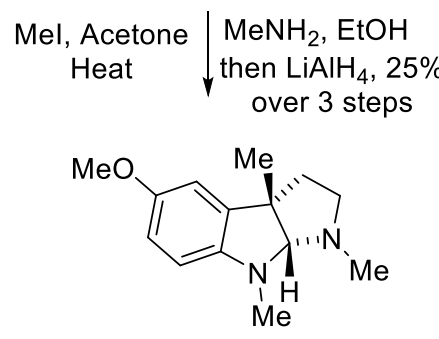

$( \pm)$-esermethole (1c)

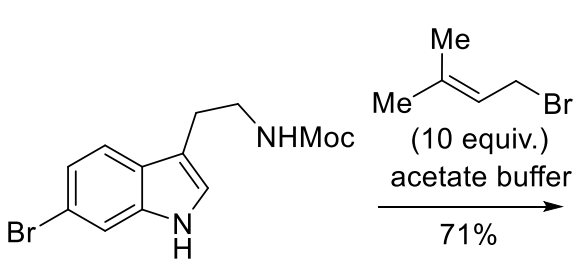

(9a)

Moc- = methyloxycarbonyl group

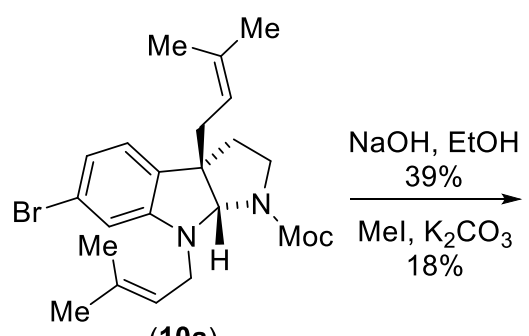

(10a)

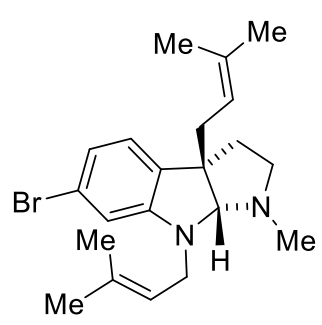

$( \pm)$-flustramine B (1g)

Scheme 4. Total synthesis of ( \pm )-esermethole (1c) by lkeda et al. and ( \pm )-flustramine B (1g) Hino et al.

In 1983, Hino and co workers ${ }^{75}$ reported that the precursor of 6-bromotryptamine derivative 9 a can be utilized for the total synthesis of $( \pm)$-flustramine B $(\mathbf{1 g})$ as shown in Scheme 4. A successive double prenylation of 9a with an excess of prenyl bromide furnished 10a, which on subsequent hydrolysis followed by a reaction with Mel completed the total synthesis of $( \pm$ )-flustramine B (1g) (Scheme 4$) .{ }^{75-76}$

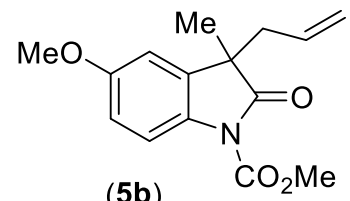

(5b)

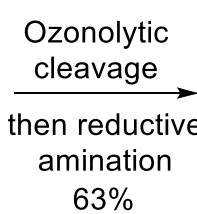
$63 \%$<smiles>CNc1ccc(OC)cc1C1(C)CCN(C)C1=O</smiles>
$\underset{\mathrm{K}_{2} \mathrm{CO}_{3}, \mathrm{MeOH}}{\longrightarrow}$
$\mathrm{Me}_{2} \mathrm{~S}, \mathrm{AlCl}_{3}$
$\mathrm{CH}_{2} \mathrm{Cl}_{2}, 63 \%$<smiles>COc1ccc(N)c(C2(C)CCN(C)C2=O)c1</smiles>

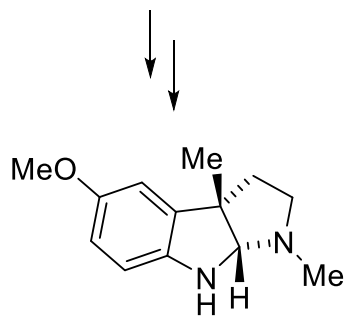

( \pm )-physostigmine (1d)

Scheme 5. Synthesis of $( \pm$ )-physostigmine (1d) by Fukumoto et al. 
Later in 1986, Fukumoto and co-workers ${ }^{77}$ have described formal total synthesis of $( \pm)$-physostigmine (1d) (Scheme 5). Ozonolysis of 2-oxindole $\mathbf{5 b}$ followed by reductive amination and ester-aminolysis afforded expected lactam carbamate (11a) in 63\% yield, which was further treated with $\mathrm{K}_{2} \mathrm{CO}_{3}$ in $\mathrm{MeOH}$ then dimethyl sulfide and aluminum trichloride in dichloromethane at room temperature furnished lactam (11b) with 63\% yield. As the total synthesis of $\left( \pm\right.$ )-physostigmine $(\mathbf{1 d})$ is reported from compound $\mathbf{1 1 b}$ by Takano group ${ }^{78}$ (1982), this effort culminated in a formal total synthesis of $\mathbf{1 d}$ (Scheme 5 ).

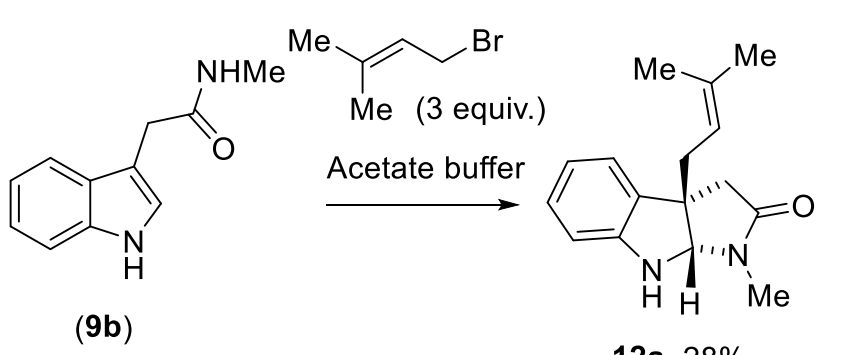

$12 \mathrm{a}, 28 \%$

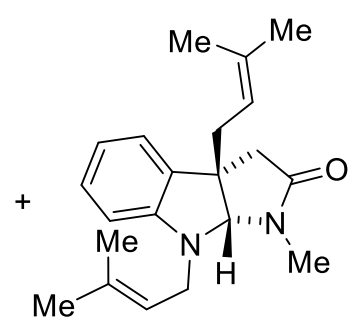

$12 \mathrm{~b}, 38 \%$

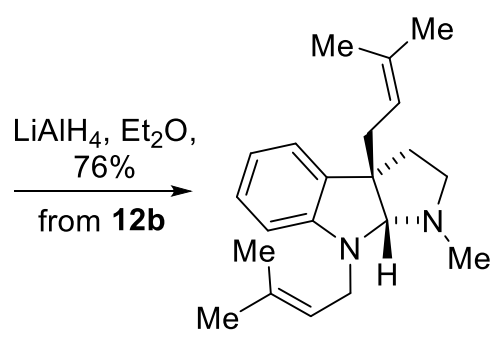

( \pm )-deromoflustramine B (1f)

Scheme 6. Synthesis of $( \pm$ )-debromoflustramine B (1f) by Christophersen et al.

In 1995, the methylamide of 3-indolylacetic acid (9b) was utilized by Christophersen, ${ }^{79}$ for a total synthesis of $( \pm$ )-debromoflustramine $B(\mathbf{1 f})$ (Scheme 6). A reaction of $9 \mathbf{b}$ with 3,3-dimethylallyl bromide afforded monoprenylated pyrroloindolone $\mathbf{1 2 a}$ and $\mathbf{1 2 b}$ (Scheme 6). Reduction of $\mathbf{1 2 b}$ with $\mathrm{LiAlH}_{4}$ completed the total synthesis of $( \pm$ )-debromoflustramine $B(\mathbf{1 f})$ in $76 \%$ yield (Scheme 6$)$.

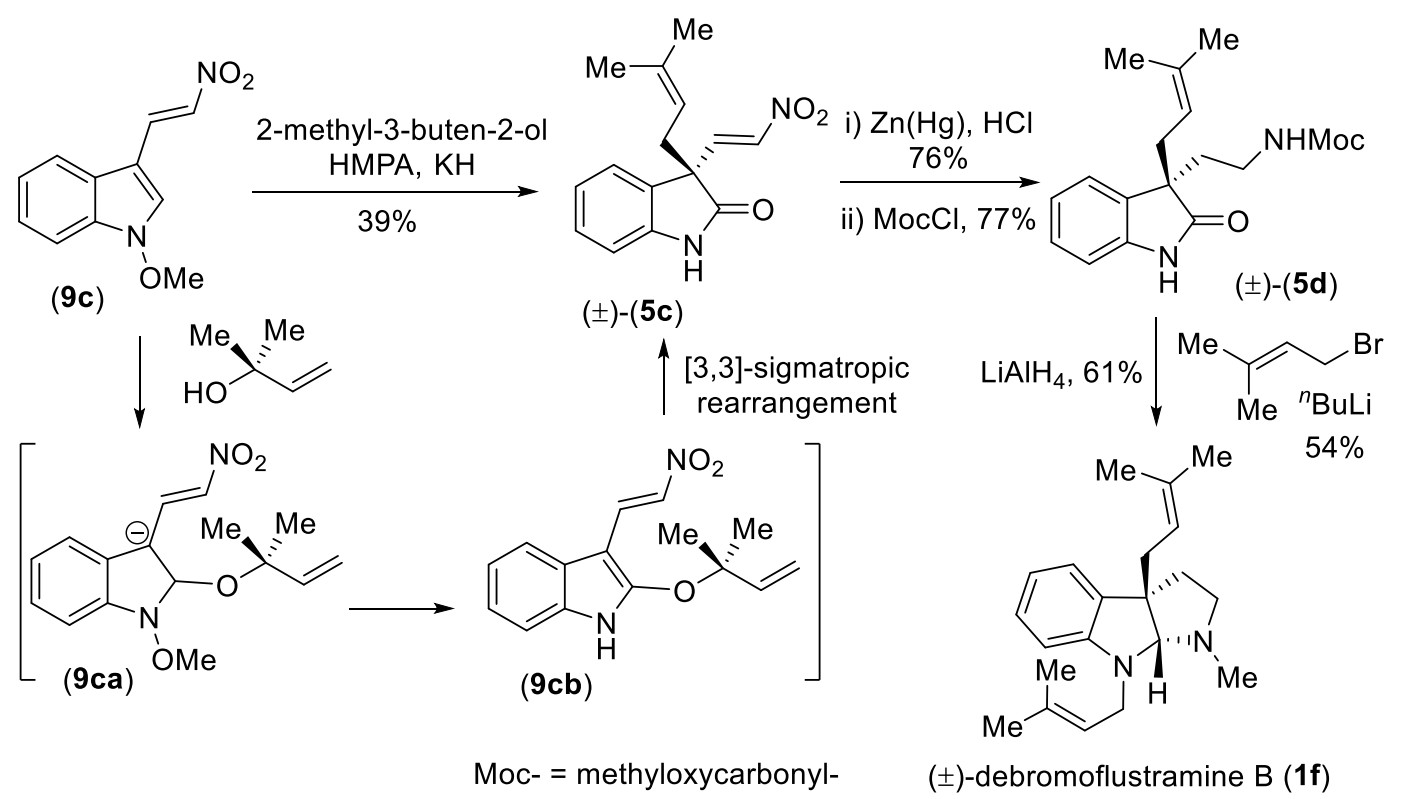

Scheme 7. Synthesis of ( \pm )-debromoflustramine B (1f) from nitrovinylindole by Somei et al.

Later in 1997, Somei and co-workers, ${ }^{80}$ successfully synthesize 3-prenyl-3-(2-nitrovinyl)-2-oxindole 5c via a Claisen type rearrangement of nitrovinylindole $9 \mathrm{cb}$ which was prepared from $9 \mathrm{c}$ with 2-methyl-2-buten-2-ol (Scheme 7). Selective reduction of the nitrovinyl group to amine was carried our using $\mathrm{Zn}-\mathrm{Hg}$ in $\mathrm{HCl}$, followed 
by a sequence that involves $N_{b}$-carbomethoxylation afforded $\mathbf{5} \mathbf{d}$ in synthetically useful yield. Finally, a reductive cyclization followed by $N$-8-prenylation afforded $( \pm$ )-debromoflustramine $B(\mathbf{1 f})$ (Scheme 7).
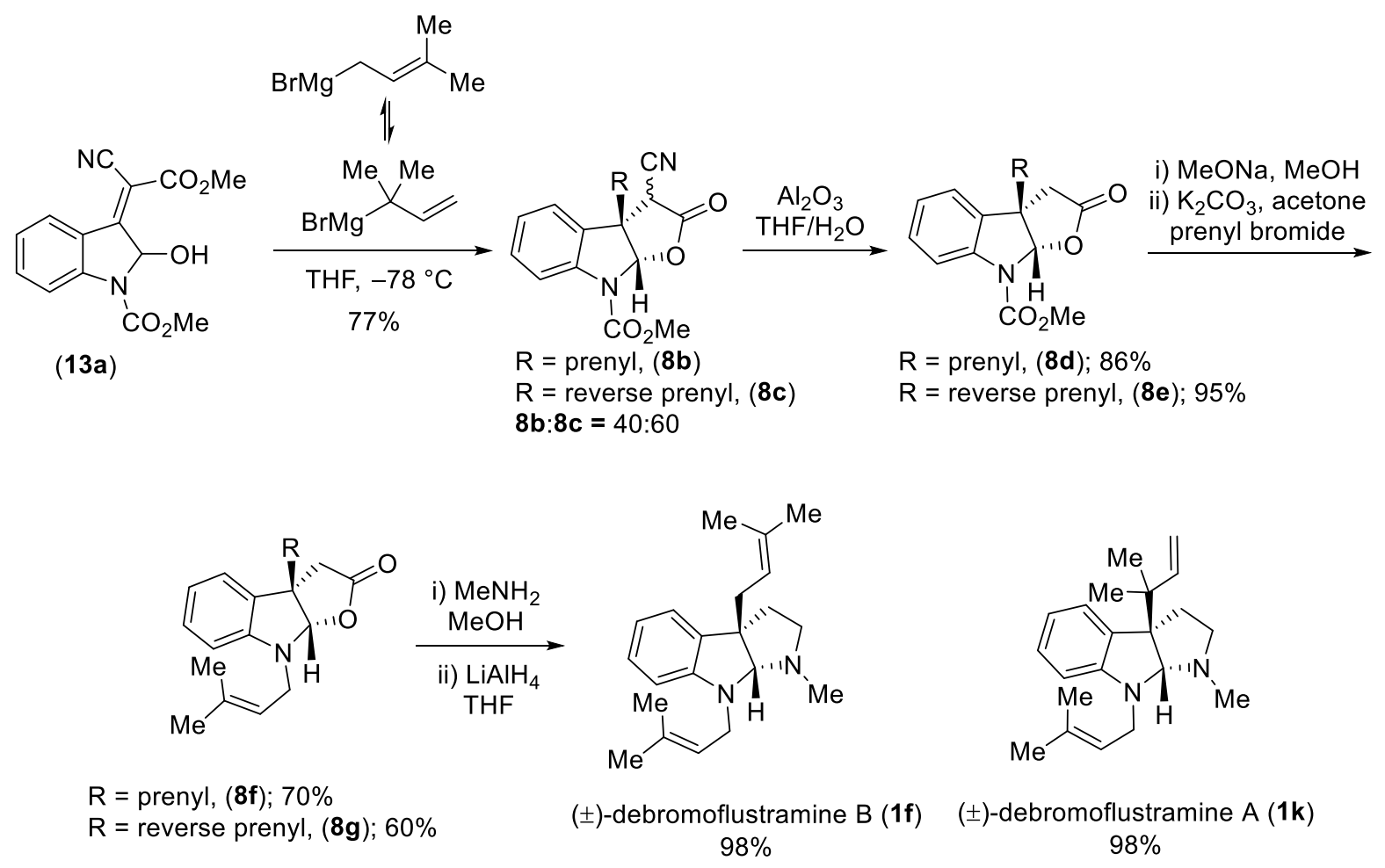

Scheme 8. Total synthesis of $( \pm$ )-debromoflustramine A (1k) and B (1f) by Joseph-Nathan et al.

Later in 1999, Joseph-Nathan and co workers ${ }^{81}$ reported a potential straightforward route to a variety of marine Flustra foliacea alkaloids (Scheme 8). Initially Grignard addition onto 2-hydroxyindolenines (13a) yielded a prenylated and reverse prenylated 2-oxofuro[2,3-b]indoles with $77 \%$ yield (8b:8c $=40: 60$ ratio). Later Hydrolytic decyanation of the $\alpha$-cyano $\gamma$-lactones in presence of alumina afforded the corresponding $\gamma$-lactone $\mathbf{8 d}$ and $\mathbf{8 e}$ in $86 \%$ and $95 \%$ yield, respectively. Later, Moc (methyloxycarbonyl) group deprotection of compounds $\mathbf{8 d}$ and $\mathbf{8 e}$ using sodium methoxide and followed by $\mathrm{N}$-alkylation by using $\mathrm{K}_{2} \mathrm{CO}_{3}$ and prenyl bromide yielded $70 \%$ and $60 \%$ of lactone $\mathbf{8 f}$ and $\mathbf{8 g}$, respectively. Finally, total syntheses of debromoflustramines $A(\mathbf{1 k})$ and B (1f) were completed from 8f-g by aminolysis using methylamine followed by $\mathrm{LiAlH}_{4}$ reduction (Scheme 8).

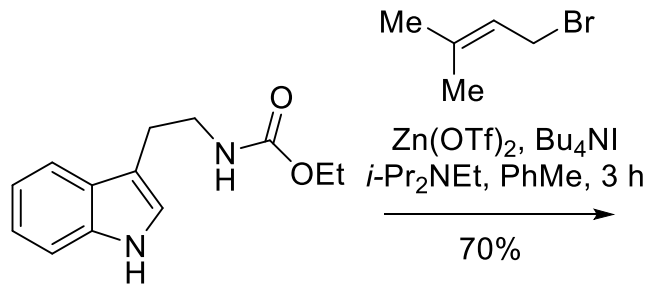

$(9 d)$

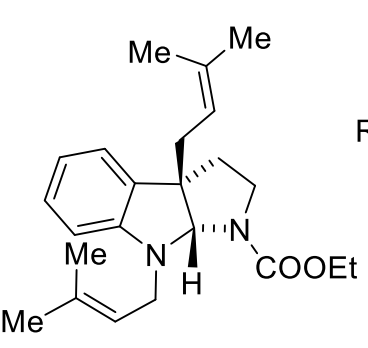

(10b)

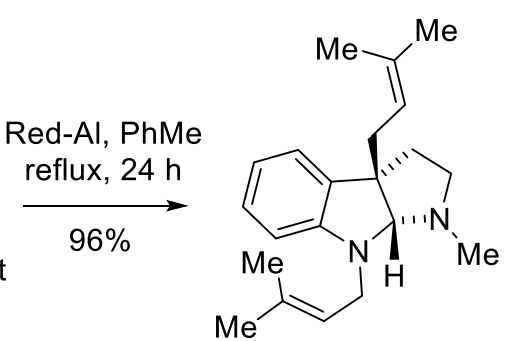

( \pm )-debromoflustramine B (1f)

Scheme 9. Synthesis of ( \pm )-debromoflustramine (1f) by Ganesan et al. 
In 2003, an efficient biomimetic approach to ( \pm )-debromoflustramine B (1f) was reported by Ganesan and co-workers $^{82}$ (Scheme 9). The total synthesis of ( \pm )-debromoflustramine $B(\mathbf{1 f})$ was accessed in two steps from tryptamin derivative 9d (Scheme 9). A zinc triflate mediated alkylation of 9d with prenyl bromide in the presence of DIPEA and tetrabutylammonium iodide gave 10b in $70 \%$ yield. Reduction of the carbamate group was performed with Red-Al to give ( \pm )-debromoflustramine B (1f) in 96\% yield. Modifications of Ganesan's approach to the synthesis of $\mathbf{1} \mathbf{f}$ were also explored recently by the groups of Menéndez ${ }^{83}$ and Mitchell. ${ }^{84}$

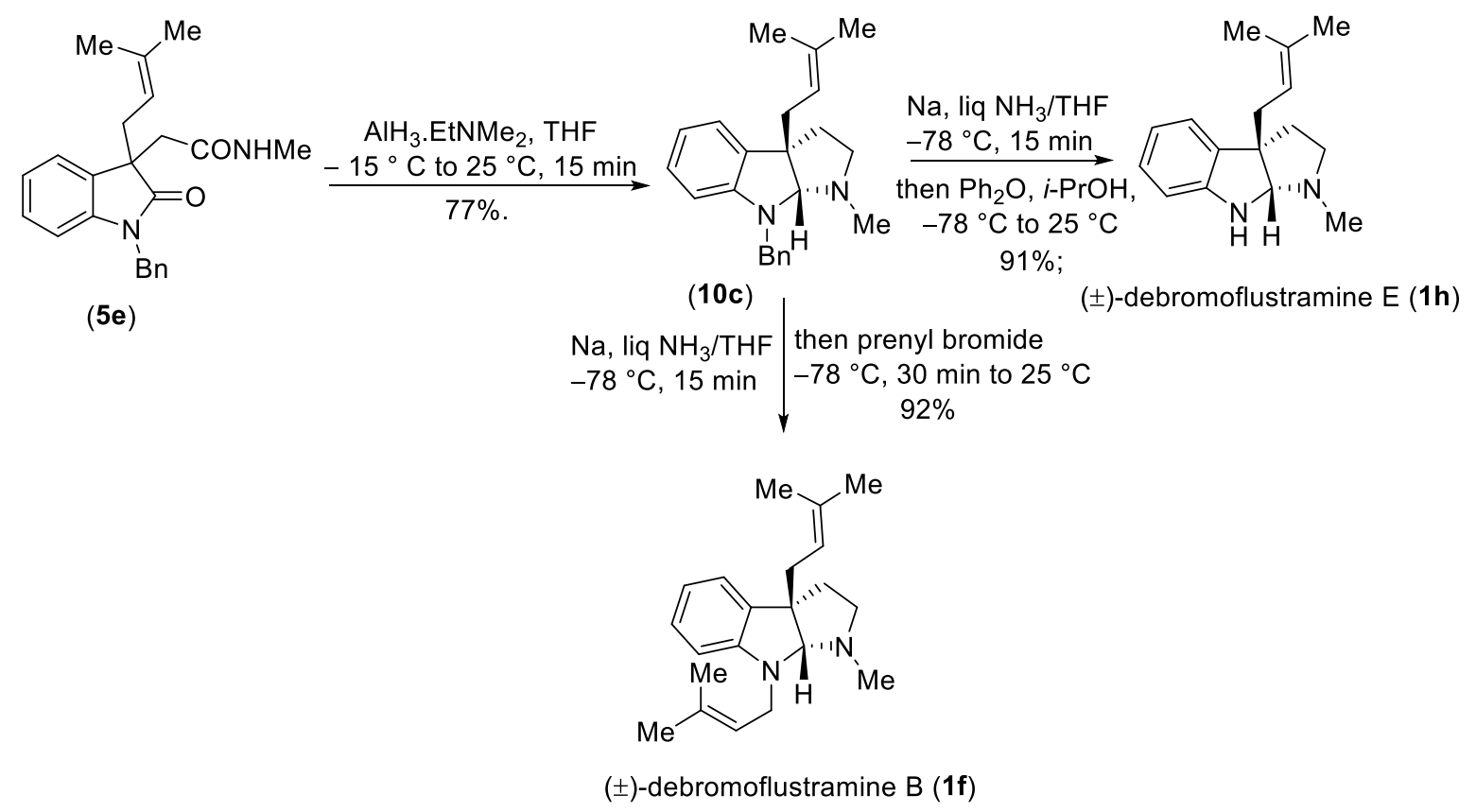

Scheme 10. Total synthesis of $( \pm)$-debromoflustramine B (1f) and E (1h) by Kobayashi et al.

Kobayashi and co workers ${ }^{85}$ have reported the complete total synthesis of $( \pm)$-debromoflustramines B (1f) and $E$ (1h) from amide intermediate (5e) in 2007 (Scheme 10). Reduction of 5e using $\mathrm{AlH}_{3}$. EtNMe $\mathrm{E}_{2}$ furnished cyclotryptamine skeleton 10c. Later to complete target molecule, compound 10c was treated under the Birch condition followed by prenylation to form ( \pm )-debromoflustramine B (1f). Also, Birch reduction of 10c completed the total synthesis of $( \pm)$-debromoflustramine $E(\mathbf{1 h})$.

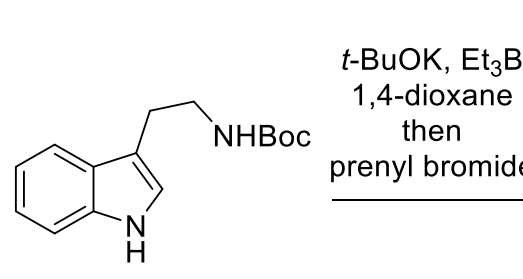

(9e)
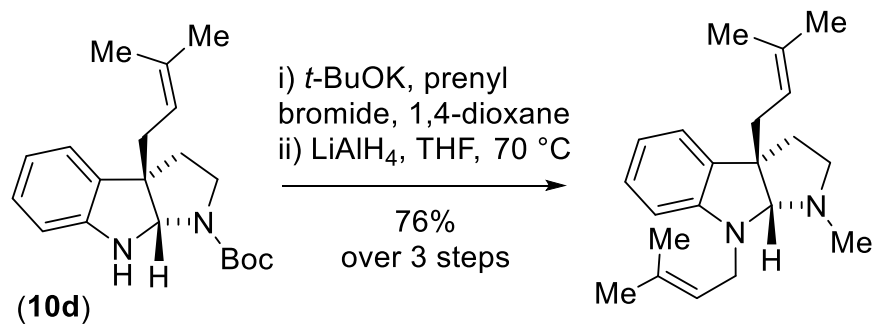

( \pm )-debromoflustramine B (1f)

Scheme 11. Synthesis of ( \pm )-debromoflustramine (1f) by Yang et al.

In 2013, Yang et. al. ${ }^{86}$ disclosed the total synthesis of ( \pm )-debromoflustramine B (1f) (Scheme 11). The reaction of $\mathrm{N}$-Boc-tryptamine (9e) and prenyl bromide in presence of triethyl borane and $t$-BuOK led to the 
formation of $\mathbf{1 0 d}$, which was subjected to further prenylation and reduction with $\mathrm{LiAlH}_{4}$ completed the total synthesis of ( \pm )-debromoflustramine B (1f) in $76 \%$ yield over 3 steps (Scheme 11).<smiles>CNc1ccc(OC)cc1</smiles>

(14a)

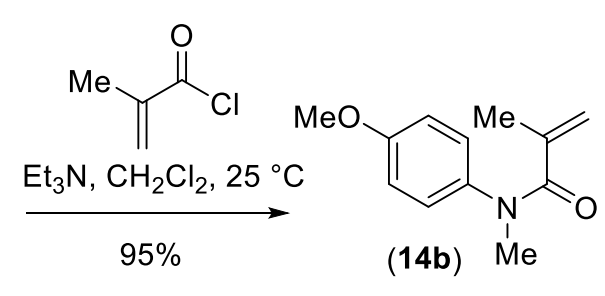

(14b) $\mathrm{Me}$

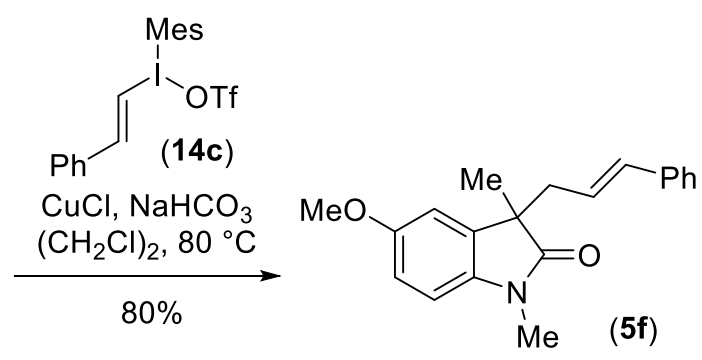

\begin{tabular}{c|c}
$\mathrm{O}_{3}, \mathrm{CH}_{2} \mathrm{Cl}_{2}, \mathrm{MeOH}$ & $\mathrm{MeNH}_{2} \mathrm{HCl}, \mathrm{Et}_{3} \mathrm{~N}$ \\
$-78{ }^{\circ} \mathrm{C}$, then $\mathrm{Me}_{2} \mathrm{~S}$ & then, $\mathrm{LiAlH}_{4}$ \\
$86 \%$ &
\end{tabular}

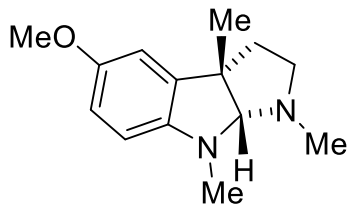

$( \pm)$-esermethole (1c)

Scheme 12. Synthesis of $( \pm)$-esermethole (1c) using copper-catalyzed vinylation by Li et al.

In 2014, Li and co-workers ${ }^{87}$ have developed an exo-selective copper-catalyzed vinylation of electrondeficient alkenes which tolerates a wide range of vinyl(aryl)iodonium triflates of types 14c (Scheme 12). Treatment of 4-methoxy- $N$-methylaniline 14a with methacryloyl chloride afforded conjugated enamide 14b with $95 \%$ yield, which was subsequently subjected to the key $\mathrm{Cu}(\mathrm{I})$-catalyzed vinylation-cyclization to provide desired 2-oxindole $\mathbf{5 f}$ in $\mathbf{8 0 \%}$ yield (Scheme 12 ). Ozonolysis of compound $\mathbf{5} \mathbf{f}$ followed by reductive amination in the presence of methylamine and $\mathrm{LiAlH}_{4}$ furnished $( \pm$ )-esermethole (1c) in $86 \%$ yield over two steps (Scheme 12).

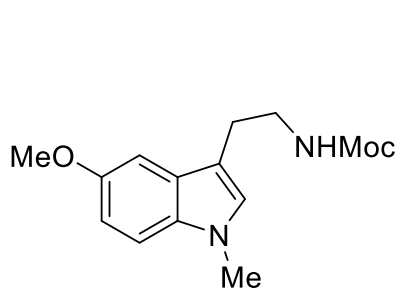

(9f)

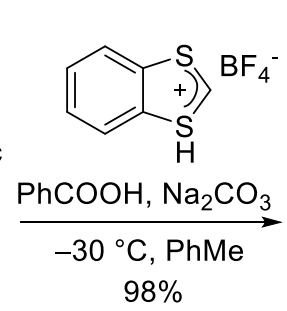

$98 \%$

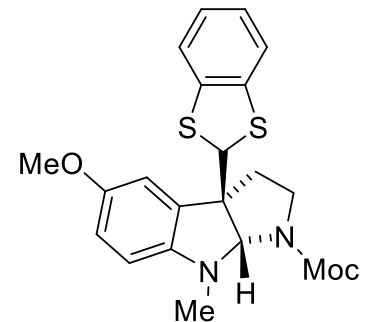

(15a)

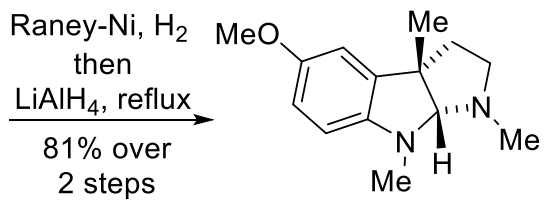

( \pm )-esermethole (1c)

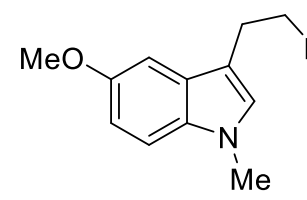

(9f)

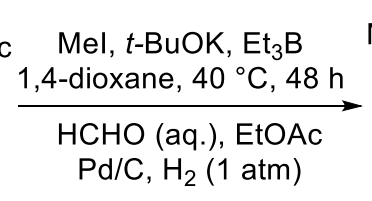

$81 \%$

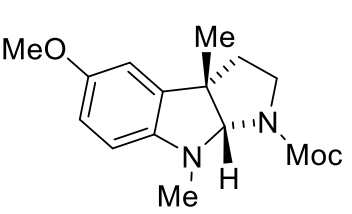

(15b)

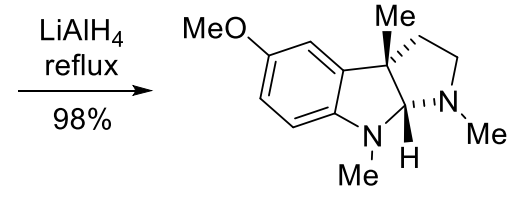

( \pm )-esermethole (1c)

Scheme 13. Synthesis of $( \pm$ )-esermethole (1c) following intramolecular cascade by You et al. 
In 2015, You et. al. ${ }^{88}$ have developed a powerful method to establish pyrroloindoline (1) skeletons by an intermolecular cascade dearomatization of indole derivative (9f) with benzodithiolylium tetrafluoroborate (Scheme 13). Treatment of compound 15a under the Raney $\mathrm{Ni} / \mathrm{H}_{2}$ followed by reduction of the methylcarbamate group with $\mathrm{LiAlH}_{4}$ afforded ( \pm )-esermethole (1c) in $98 \%$ yield.

Later, the same group have developed another strategy for the synthesis of C3-methyl-substituted hexahydropyrrolo[2,3-b]indole alkaloid ( \pm )-esermethole (1c) (Scheme 13). Compound 15b was synthesized from compound 9 f in $81 \%$ yield, which was treated with $\mathrm{LiAlH}_{4}$ to complete ( \pm )-esermethole (1c) in $98 \%$ yield (Scheme 13). ${ }^{89}$

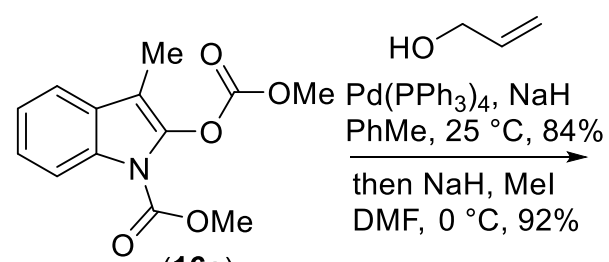

(16a)

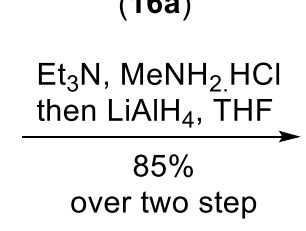

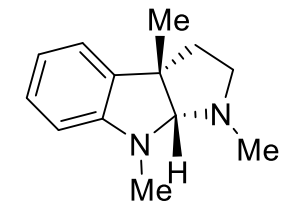

( \pm )-deoxyeseroline (1a)

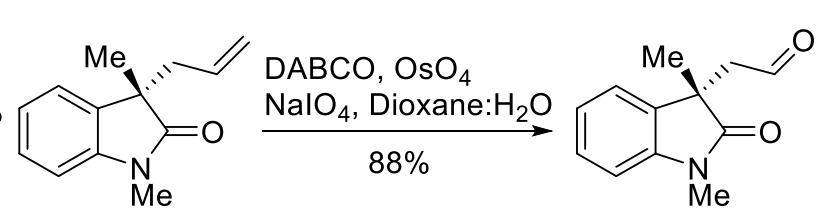

(5g)

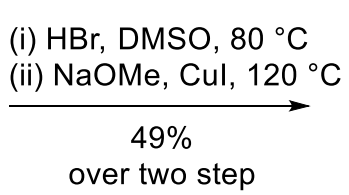

over two step

(16b)

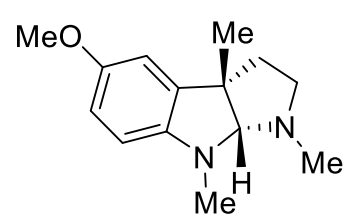

(士)-esermethole (1c)

Scheme 14. Synthesis of $( \pm)$-esermethole (1c) via a key deacylative pathway by Bisai et al.

In 2018, Bisai and co workers ${ }^{90}$ have developed an efficient $\mathrm{Pd}(0)$-catalyzed chemoselective deacylative allylation of $\mathrm{N}$-acyl 2-oxindole with unprotected allyl alcohol (Scheme 14). This methodology was applied for a total synthesis of $( \pm$ )-deoxyeseroline (1a) following a key oxidative cleavage followed by reductive cyclization. Further, the total synthesis of $( \pm$ )-esermethole (1c) was achieved from ( \pm )-deoxyeseroline (1a) in two steps.

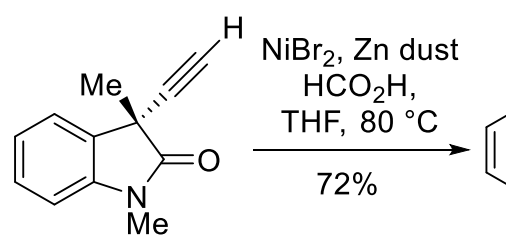

(5h) (5i)
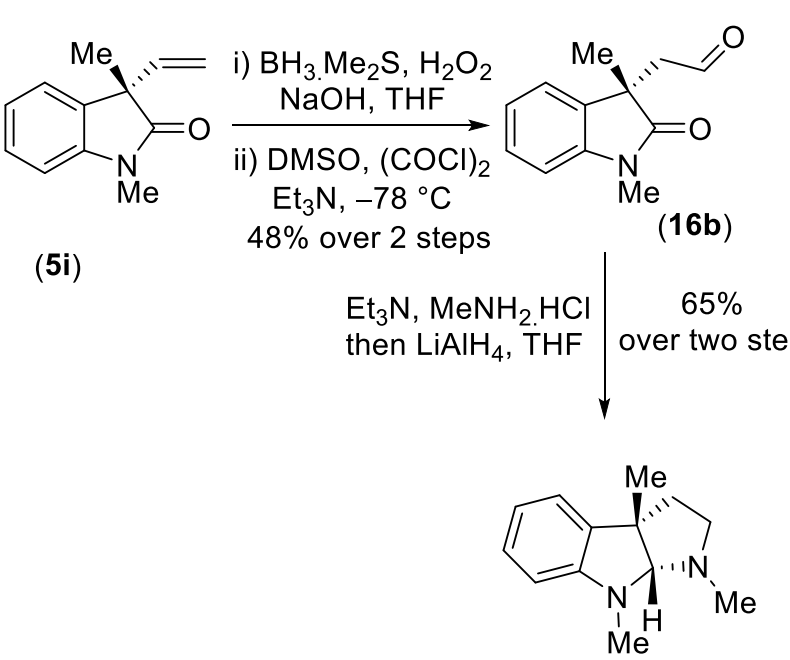

( \pm )-deoxyeseroline (1a)

Scheme 15. Synthesis of ( \pm )-esermethole (1c) via a key electrophilic alkynylation pathway by Bisai et al. 
In 2020, Bisai et. al. have reported a direct alkynylation at C3 position of 3-methyl 2-oxindoles using a 5(alkynyl)dibenzothiophenium triflate afforded compound $5 \mathrm{~h}$ (Scheme 15). Later Nickel catalyzed controlled hydrogenation of compound $\mathbf{5 h}$ followed by hydroboration oxidation and further oxidation lead to form aldehyde intermediate $\mathbf{1 6 b}$. Next, a reductive amination of $\mathbf{1 6 b}$ with methylamine followed by a reductive cyclization by $\mathrm{LiAlH}_{4}$ to furnish ( \pm )-deoxyeseroline (1a) (Scheme 15). ${ }^{91}$

\subsection{Stereocontrolled synthesis of hexahydropyrrolo[2,3-b]indole alkaloids}

The first enantioselective synthesis of (-)-physostigmine (1d) was reported by Takano group, ${ }^{78}$ from a readily available chiral synthon (S)-(-)-benzyl-2,3-epoxypropyl ether (-)-17a (Scheme 16). Compound (-)-17a was reacted with in-situ generated carbanion of 3-methoxy benzyl cyanide 17b using LDA (lithium amide of diisopropylamine) to produce cyano-alcohol (-)-17c as a mixture of diastereomer (Scheme 16). Later hydrolysis of $(-)-17 c$ yielded $\gamma$-lactone $(-)-\mathbf{1 7 d}$ in $63 \%$ over 3 steps. The stereoselective insertion of methyl group from the less hindered face followed by hydrogenolysis in presence of $\mathrm{H}_{2}$ gas and catalytic $\mathrm{Pd}-\mathrm{C}$ afforded hydroxyl lactone (-)-17e.

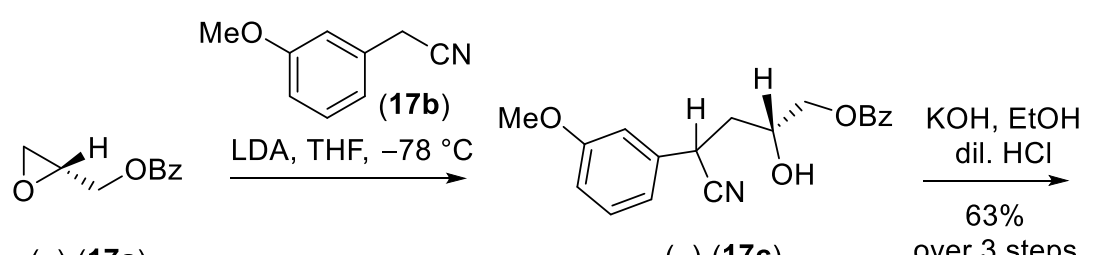

$(-)-(17 a)$

$(-)-(17 c)$

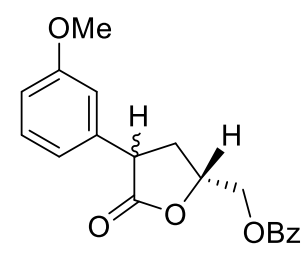

$(-)-(17 d)$
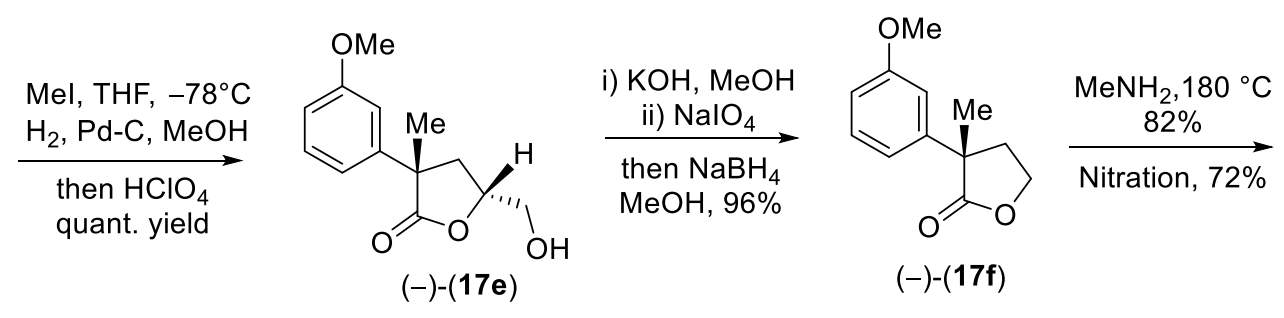

$(-)-(17 f)$

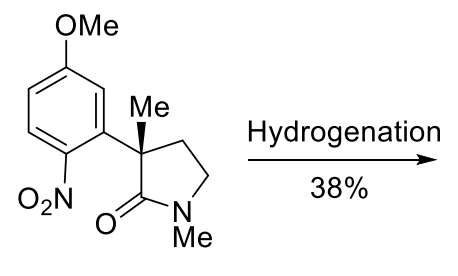

$(-)-(17 g)$
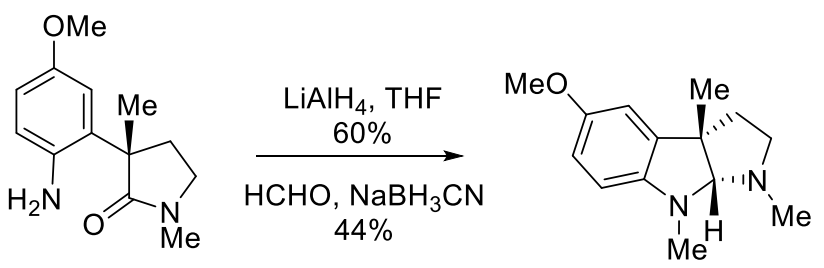

$(-)-(11 b)$

(-)-esermethole (1c)

Scheme 16. First enantioselective synthesis of (-)-esermethol (1c) by Takano et al.

After hydrolysis oxidative cleavage with $\mathrm{NaIO}_{4}$ and reduction with $\mathrm{NaBH}_{4}$ followed by acid work up to furnished the compound (-)-17f (Scheme 16). Further, condensation of the lactone (-)-17f with $40 \% \mathrm{MeNH}_{2}$ in water at $180^{\circ} \mathrm{C}$ afforded lactam, which was reacted with the cupric nitrate tetrahydrate in $\mathrm{Ac}_{2} \mathrm{O}$ to furnish (-)$\mathbf{1 7 g}$. Platinum catalyzed hydrogenation of $(-)-\mathbf{1 7 g}$ furnished amine derivative (-)-11b which under reductive cyclization and followed by $N$-methylation lead to form (-)-esermethole 1c (Scheme 16).

In 1991, Wong et. al. have ${ }^{92}$ described an enantioselective synthesis of (-)-esermethole (1c) (Scheme 17). Asymmetric alkylation of oxindole $\mathbf{5} \mathbf{j}$ with chloro acetonitrile in the presence phase transfer catalyst $\mathbf{L}$ yielded $83 \%$ of nitrile $\mathbf{5 k}$ with $\mathbf{7 3 \%}$ ee (Scheme 17 ). Later, crude nitrile $\mathbf{5 k}$ was reduced by platinum catalyzed hydrogenation to the corresponding primary amine as an optically enriched mixture. Treatment of the amine 
with dibenzoyl-D-tartaric acid in acetonitrile followed by a single recrystallization of the diastereomeric salt gave $48 \%$ yield of optically pure tartrate salt. Further $\mathrm{NaOH}$ treatment afforded optically pure amine (S)-5I, which was further treated ClCOOMe to form carbamate followed by reductive cyclization to furnish (-) esermethole (1c) (Scheme 17).
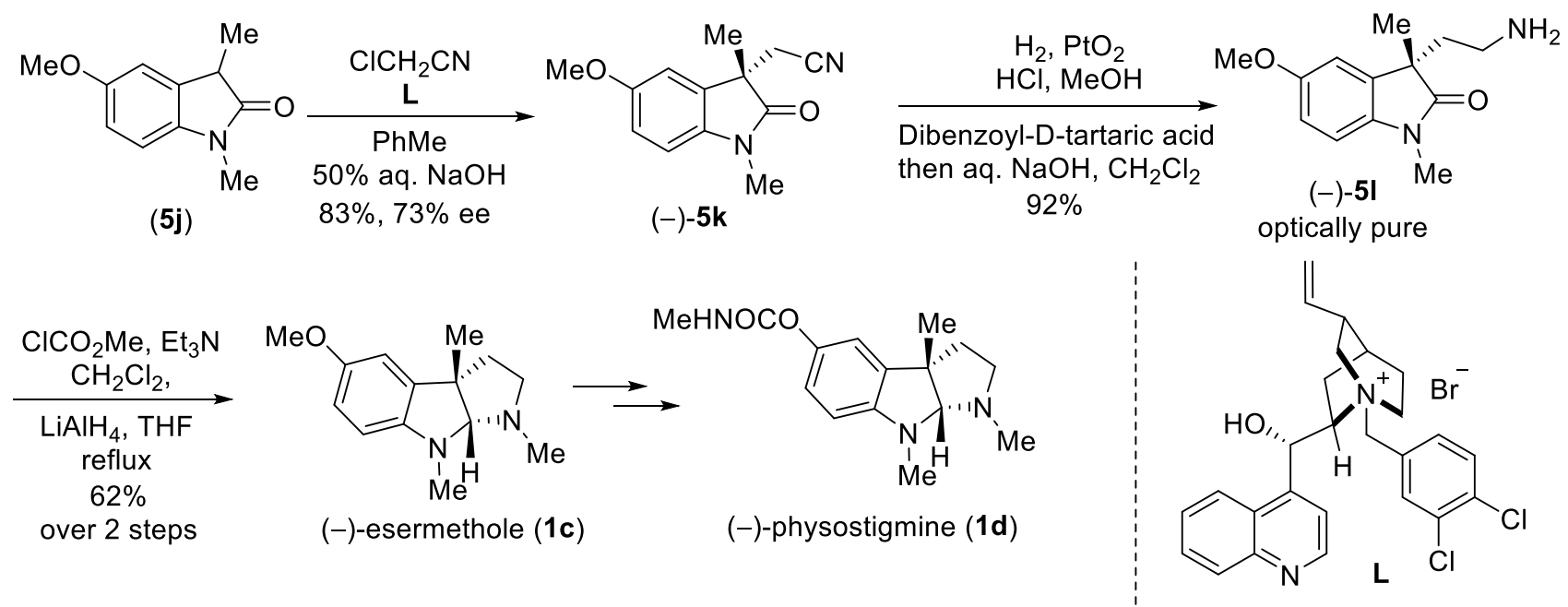

Scheme 17. Chiral PTC mediated synthesis of (-)-esermethole (1c) and (-)-physostigmine (1d) by Wong et al.
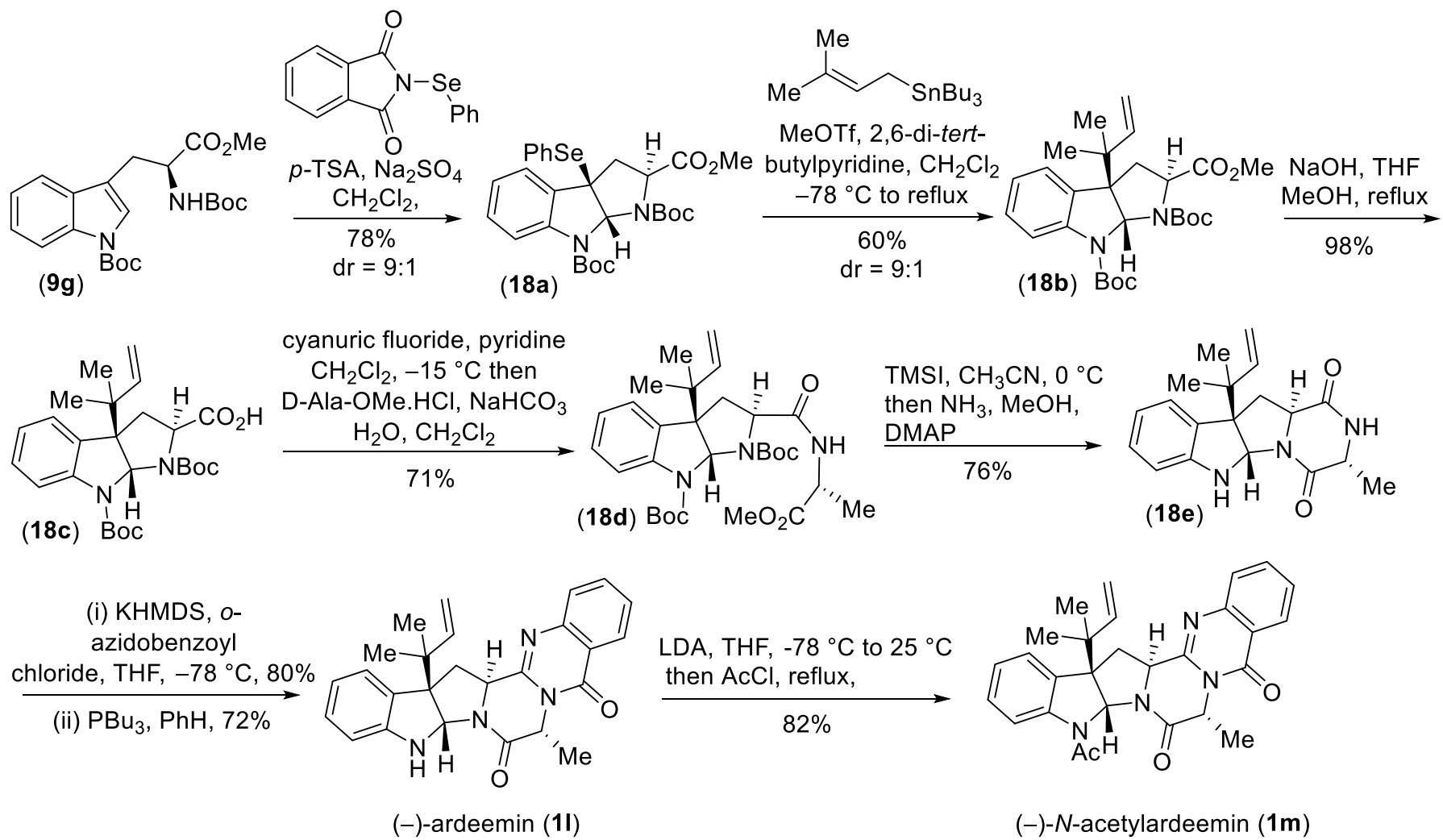

LDA, THF, $-78{ }^{\circ} \mathrm{C}$ to $25^{\circ} \mathrm{C}$ then $\mathrm{AcCl}$, reflux,

$82 \%$

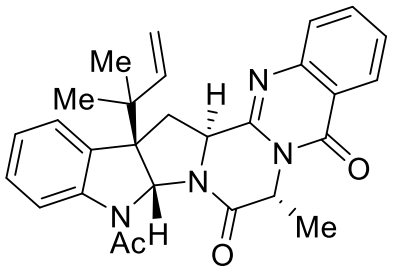

$(-)-N$-acetylardeemin $(\mathbf{1 m})$

Scheme 18. Total synthesis of (-)-ardeemin (1) and (-)-N-acetylardeemin (1m) by Danishefsky et al. 
In 1994, Danishefsky and co-workers ${ }^{93}$ have reported the total syntheses of ardeemin (1) and 5- $N$ acetylardeemin $(\mathbf{1 m})$. Bis-(Boc)tryptophan methyl ester $\mathbf{9 g}$ was converted to 3-selenenylated pyrroloindole 18a (Scheme 18). Treatment of 18a with methyl triflate and prenyl tributyl stannane furnished the desired reverse prenylated product $\mathbf{1 8 b}$ with $60 \%$ yield and 9:1 dr. After saponification of $\mathbf{1 8 b}$, coupling with D-alanine methyl ester, using standard agents afforded 18d (Scheme 18). The diketopiperazine 18e was obtained in 76\% yield upon deprotection of Boc group and ammonia-DMAP-induced cyclization. Following o-azidobenzoyl chloride acylation reaction, the resultant compound was reacted with tributylphosphine in benzene to afford ardeemin (1) in 56\% yield from $\mathbf{1 8 e}$. Finally, acylation of $\mathbf{1 l}$ provided 5 -N-acetylardeemin (1m) in $82 \%$ yield (Scheme 18).

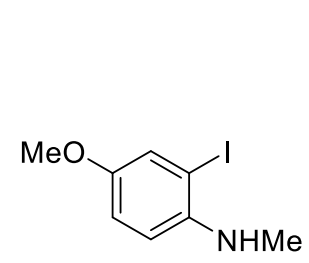

(19a)

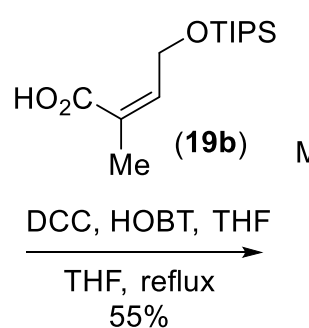

$55 \%$

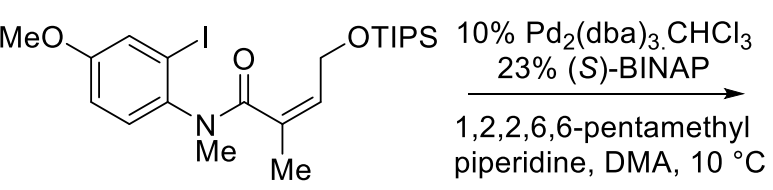

(19c)
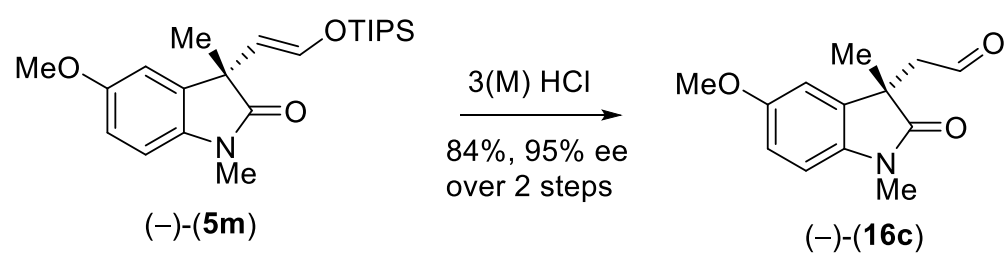

$(-)-(16 c)$
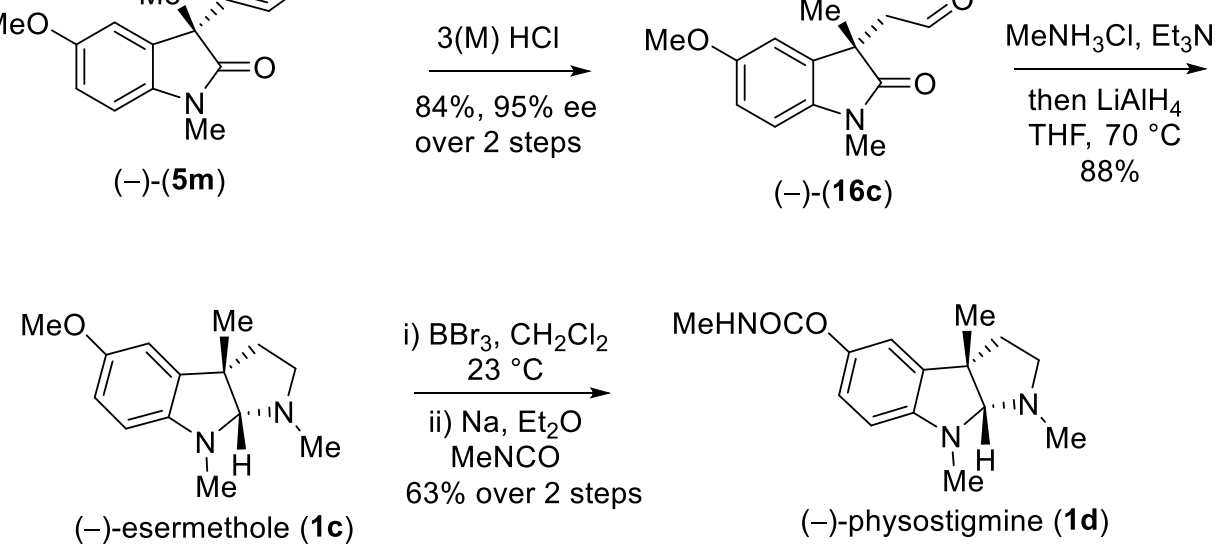

$63 \%$ over 2 steps

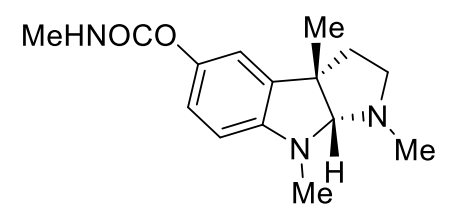

(-)-physostigmine (1d)

Scheme 19. Asymmetric Heck cyclization assisted total synthesis of (-)-physostigmine (1d) by Overman et al.

In 1998, Overman et. al. have ${ }^{94}$ disclosed asymmetric approach to hexahydropyrrolo[2,3-b]indole alkaloid, (-)-physostigmine (1d) (Scheme 19). Asymmetric Heck cyclization of 19c with 20\% Pd-(S)-BINAP [formed in situ from $10 \% \mathrm{Pd}_{2}(\mathrm{dba})_{3} . \mathrm{CHCl}_{3}$ and 23\% (S)-BINAP] afforded predominantly (diastereoselectivity = 98:2) the oxindole $(E)$-enoxysilane $(S)-5 \mathrm{~m}$ which upon treatment with dilute $\mathrm{HCl}$ to provide oxindole aldehyde $(S)$-16c in $84 \%$ yield and $95 \%$ ee (Scheme 19). Later, condensation with methylamine followed by reduction of crude imine with excess $\mathrm{LiAlH}_{4}$ in refluxing THF afforded (-)-esermethole (1c), Finally, $\mathrm{BBr}_{3}$ mediated demethylation and followed by the treatment with $\mathrm{NaH}$ and methyl isocyanate afforded (-)-physostigmine (1d) (Scheme 19).

In 2004, MacMillan and co-workers ${ }^{95}$ have reported total synthesis of (-)-flustramine B (1g) following a key Michael addition/cyclization to construct the pyrroloindoline core via iminium catalysis pathway (Scheme 20). 6-Bromo tryptamine derivative $9 \mathrm{~g}$ ' was reacted with acrolein in the presence of imidazolidinone catalyst, followed by reduction of formyl group by $\mathrm{NaBH}_{4}$ yielded $10 \mathrm{e}$ in $78 \%$ yield with $90 \%$ ee. Later, compound $10 \mathrm{e}$ was converted to terminal olefin (-)-10f in two steps over $89 \%$ yield. Cross-metathesis of 10f with 2-methyl-2butene in the presence of catalytic Grubbs $2^{\text {nd }}$ genration catalyst afforded $(-)-10 \mathrm{~g}$ in $94 \%$ yield. Finally, Boc 
group deprotection followed by $N$-methylation under reductive amination afforded (-)-flustramine B (1g) (Scheme 20).

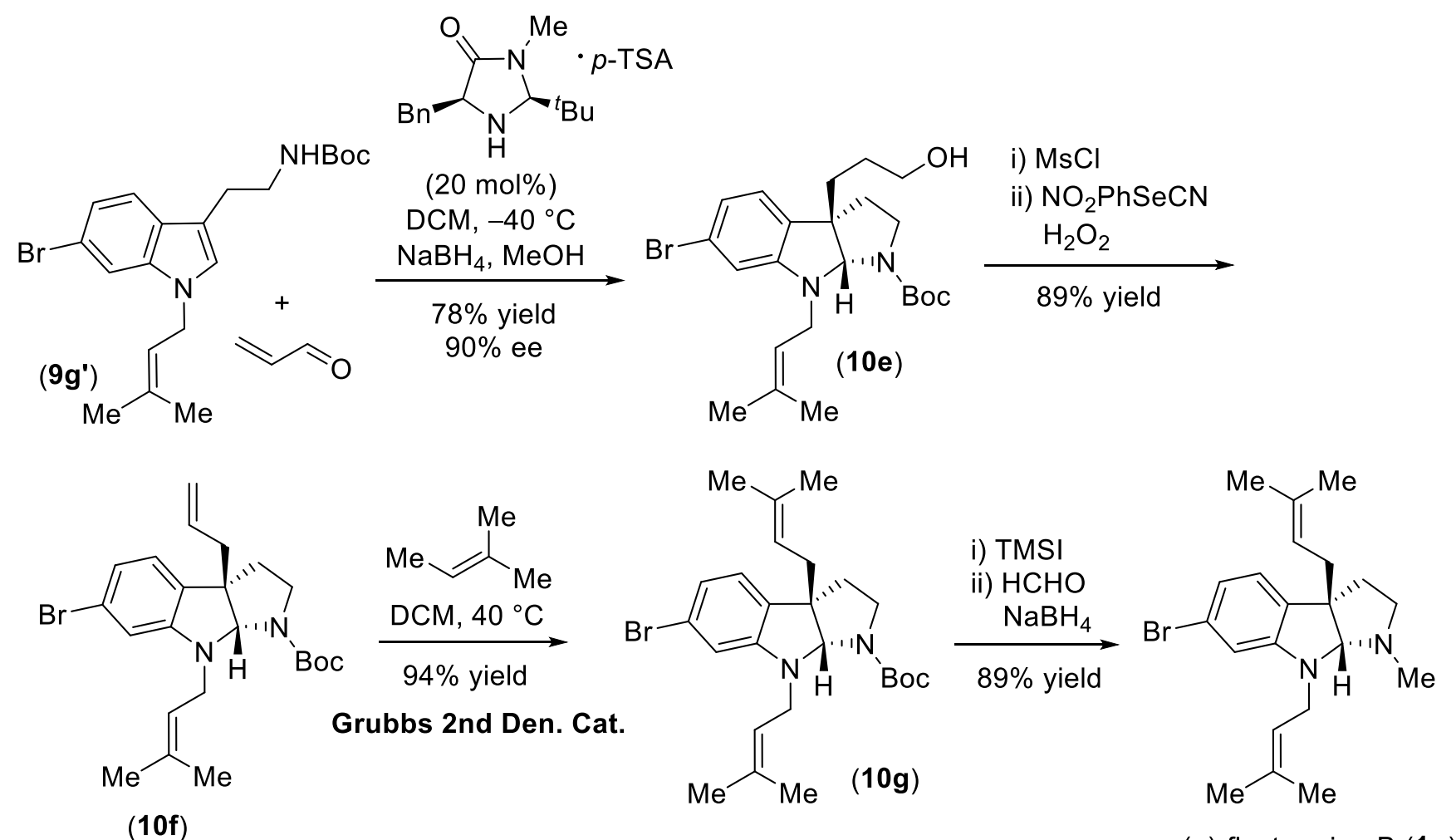

(-)-flustramine B (19)

Scheme 20. MacMillan's organocatalyzed synthesis of (-)-flustramine B (1g).

In 2006, Trost and co-workers ${ }^{96}$ have developed a Pd-catalyzed C-3 allylation of 3-substituted indole $9 \mathrm{~h}$ to give the corresponding 3,3-disubstituted indolines (-)-20a in 84\% ee (Scheme 21). Enantioenriched compound (-)-20a was treated tetrabutylammonium hydrogen monopersulfate (oxone) and acetic acid give oxindole (-)$\mathbf{1 6 d}$ in $\mathbf{7 9 \%}$ yield. Later, $N$-Methylation followed by oxidative cleavage lead to form aldehyde $(-)-\mathbf{1 6 b}$, which was further react with methyl amine followed reductive cyclization furnished (-)-esermethole (1c) (Scheme 21).

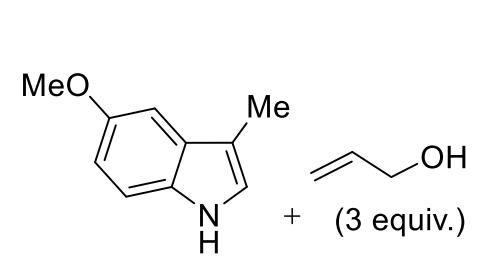

(9h)

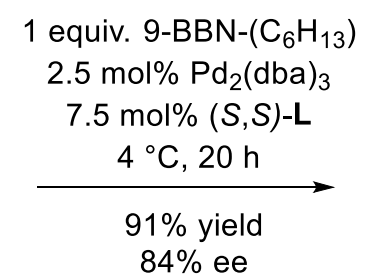

$84 \%$ ee

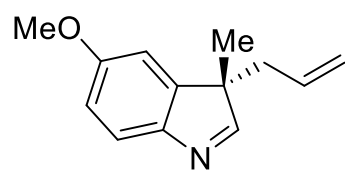

$(-)-20 a$

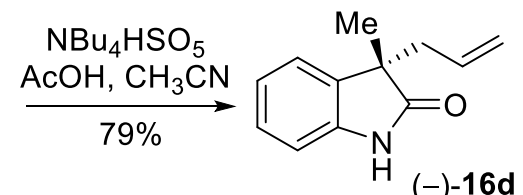

$(-)-16 d$

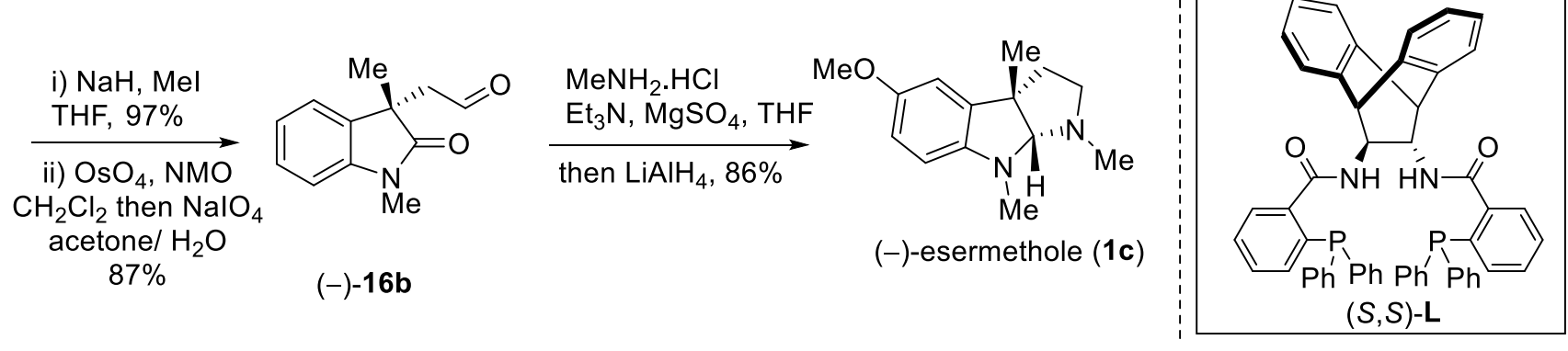

Scheme 21. enantioselective C-3 allylation directed total synthesis of (-)-esermethole (1c) by Trost et al. 


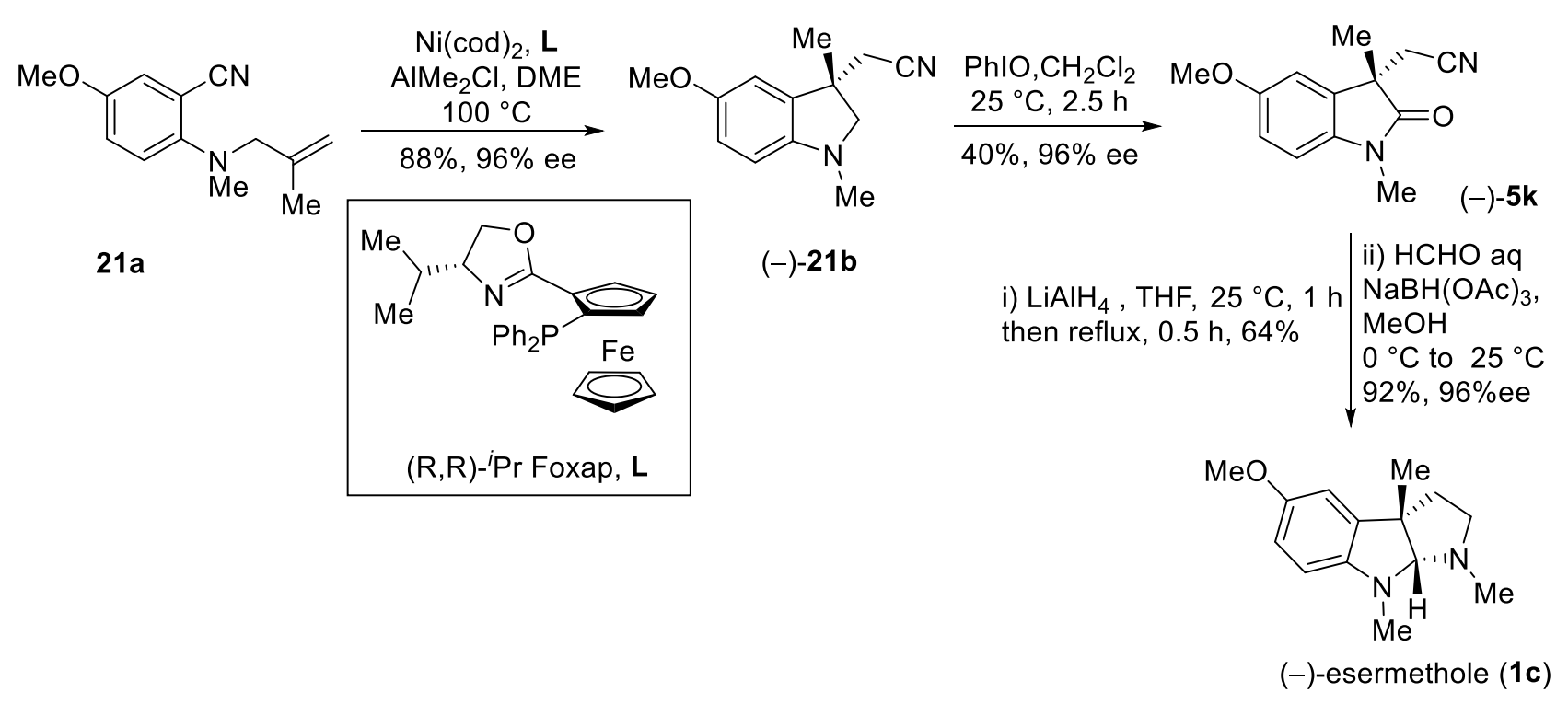

Scheme 22. Nickel catalyzed total synthesis of (-)-esermethole (1c) by Nakao et al.

In 2008, Nakao and co workers $^{97}$ have demonstrated a Nickel/AlMe ${ }_{2} \mathrm{Cl}$-catalyzed intramolecular arylcyanation of alkenes to get $\mathbf{2 1 b}$ in $\mathbf{9 6 \%}$ ee (Scheme 22). Oxidation of the C-2 position of indoline $\mathbf{2 1 b}$ afforded 2 -oxindole (-)-5k with $40 \%$ yield. Later, cyanide reduction followed by cyclization in presence of $\mathrm{LiAlH}_{4}$, and then $\mathrm{N}$-methylation completed the total synthesis of (-)-esermethole (1c) (Scheme 22).

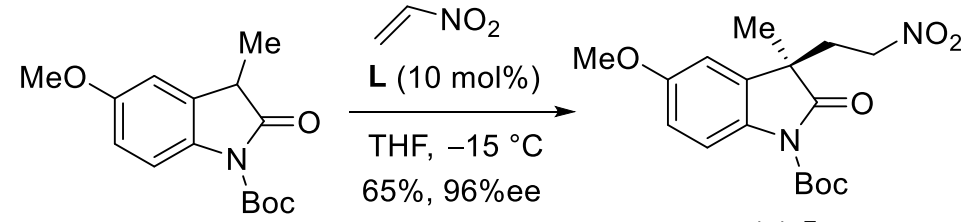

$\left(5 j^{\prime}\right)$

$(+)-5 m$<smiles>CN(C)[C@@H]1CCCC[C@H]1NC(=S)Nc1cc(C(F)(F)F)cc(C(F)(F)F)c1</smiles>

$\mathbf{L}$

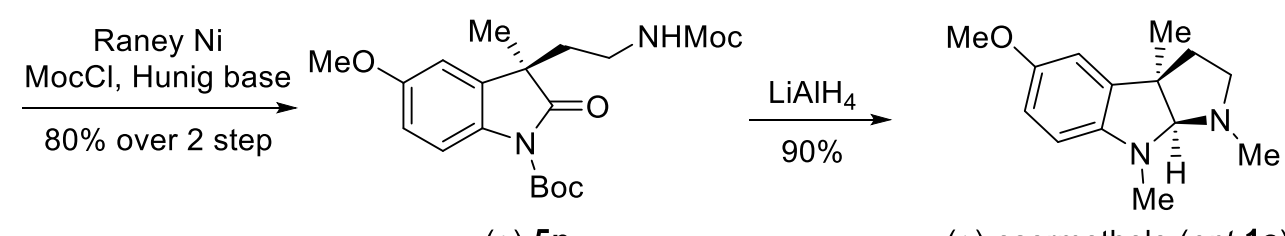

$(+)-5 n$

(+)-esermethole (ent-1c)

Scheme 23. Synthesis of (+)-esermethole ent-(1c) and (+)-physostigmine ent-(1d) by Barbas III et al.

In 2009, Barbas III and co-workers ${ }^{98}$ have demonstrated organocatalytic approach to the hexahydropyrrolo[2,3-b] indole alkaloid via a 1,4-addition of oxindole $5 \mathbf{j}$ ' on to nitroethylene (Scheme 23). This reaction afforded compound (+)-5m in $65 \%$ yield with $96 \%$ ee (after one recrystallization). Raney nickel reduction of the nitro group followed by a reaction of resultant amine with methyl carbamate provided the key intermediate (+)-5n in $80 \%$ over 2 steps, which underwent reductive cyclization with $\mathrm{LiAlH}_{4}$ to afford (+)esermethole [ent-(1c)] in 90\% yield (Scheme 23 ). 


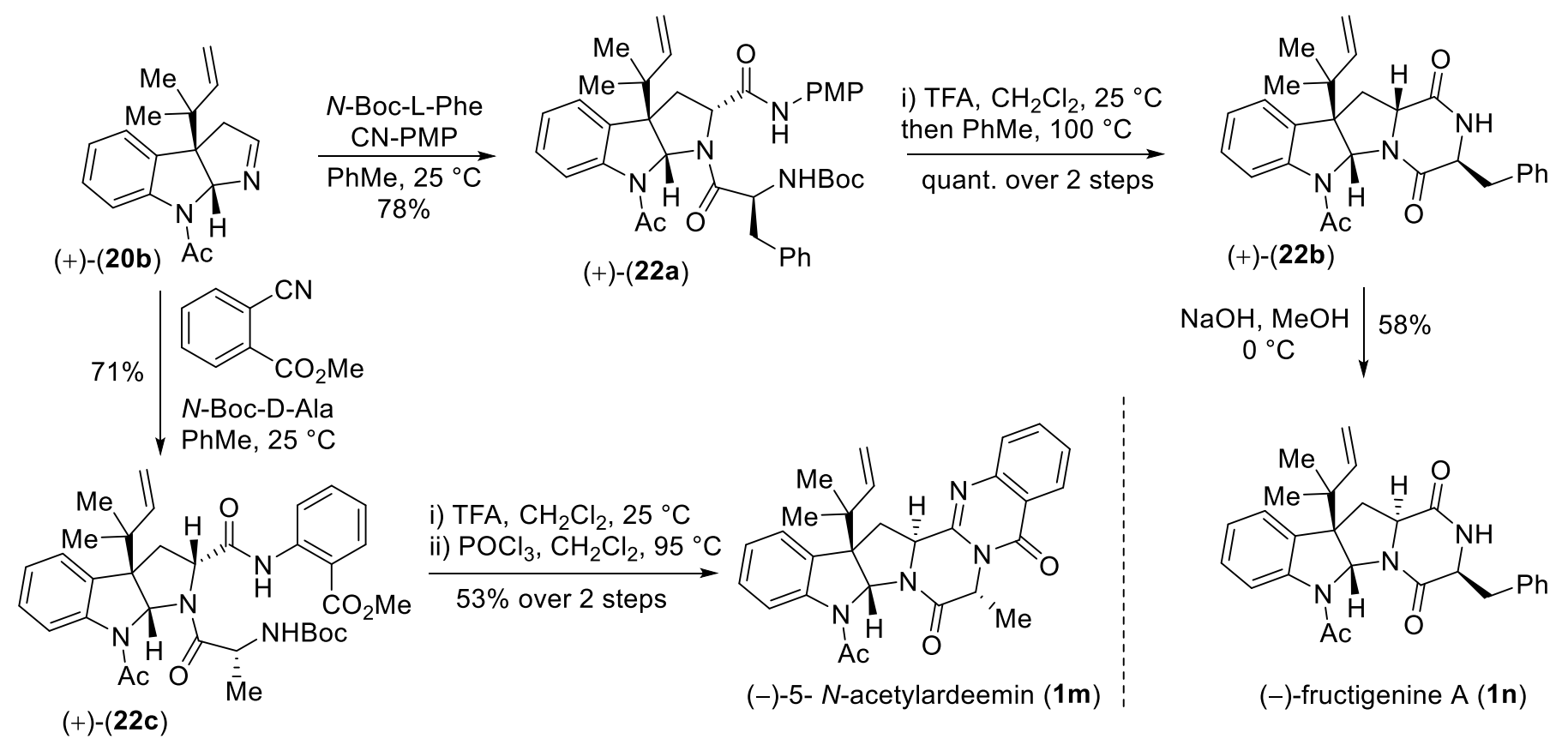

Scheme 24. Total synthesis of (-)-5-N-acetylardeemin (1m) by Kawasaki et al.

In 2010, Kawasaki et. al. ${ }^{99}$ have demonastrated the first total synthesis of (-)-fructigenine (1n) and a novel approach to $(-)-5-N$-acetylardeemin $(\mathbf{1 m})$ through a common imine intermediate $(+)-\mathbf{2 0 b}$. They have synthesized pyrroloindoline imine (+)-20b intermediate starting from 1-acetylindolin-3-one via a key domino olefination/isomerization/Claisen rearrangement (OIC) followed by reductive cyclization and regioselective oxidation process. With this key intermediate in hand, they have completed the total synthesis of fructigenine A (1n). N-Boc-L-phenylalanine and $p$-methoxyphenyl (PMP) isonitrile were reacted with (+)-20b to afford dipeptide $(+)-22 a$ in $78 \%$ yield via Ugi three-component reaction. Removal of Boc group of $(+)$-22a with TFA leads to smooth cyclization in refluxing toluene afforded diketopiperazine (+)-22b. Later, $\mathrm{NaOH}$ mediated epimarization of (+)-22b completed the total synthesis of (-)-fructigenine (1n). Along similar line, (-)-5-Nacetylardeemin $(\mathbf{1 m})$ was synthesized from the intermediate (+)-20b (Scheme 24). Compound (+)-20b was reacted with $\mathrm{N}$-Boc-D-alanine and isonitrile to provide $(+)-22 \mathrm{c}$. Further, $(+)-22 \mathrm{c}$ was reacted with trifluoroacetic acid followed by a reaction with phosphorus oxychloride to furnished the desired product (-)-5$\mathrm{N}$-acetylardeemin (1m) (Scheme 24).
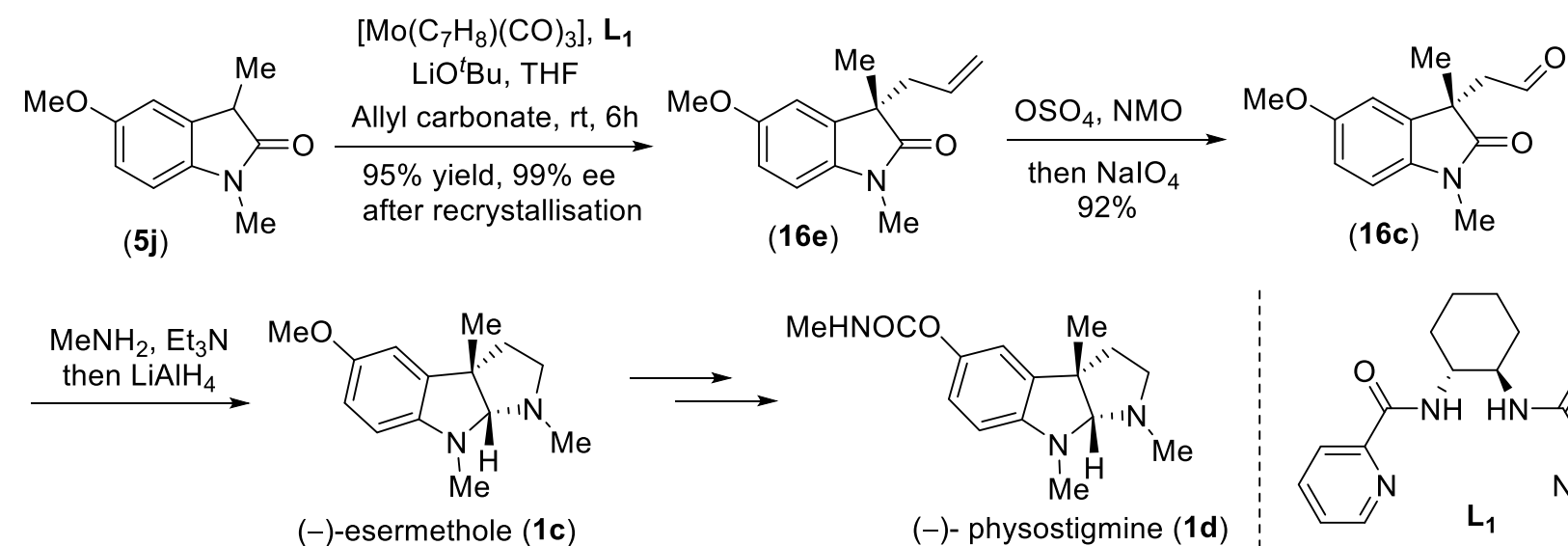

(-)- physostigmine (1d)

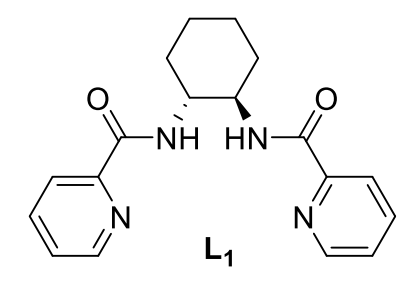

Scheme 25. Mo-catalyzed asymmetric synthesis of (-)-esermethole (1c) by Zhang et al. 
In 2011, Trost and Zhang $^{100}$ have developed enantioselective Mo-catalyzed asymmetric allylic alkylation (AAA) reactions for the generation of quaternary stereocenters at the 3-position of 3-alkyl oxindole 5j (Scheme 25). Asymmetric allylation of $\mathbf{5 j}$ under the optimized conditions proceeded to afford (-)-16e with $95 \%$ yield and $99 \%$ ee (after recrystallization). Oxidation of the allylated product (-)-16e, $\left(\mathrm{OsO}_{4}, \mathrm{NMO}\right.$, and then $\left.\mathrm{NalO}_{4}\right)$ provided the aldehyde (-)-16c in $92 \%$ yield. Later imine formation with methyl amine and followed by reductive cyclization afforded (-)-esermethole (1c), which had been transformed to (-)-physostigmine (1d) and (-)-phenserine (1e), in two steps (Scheme 25).
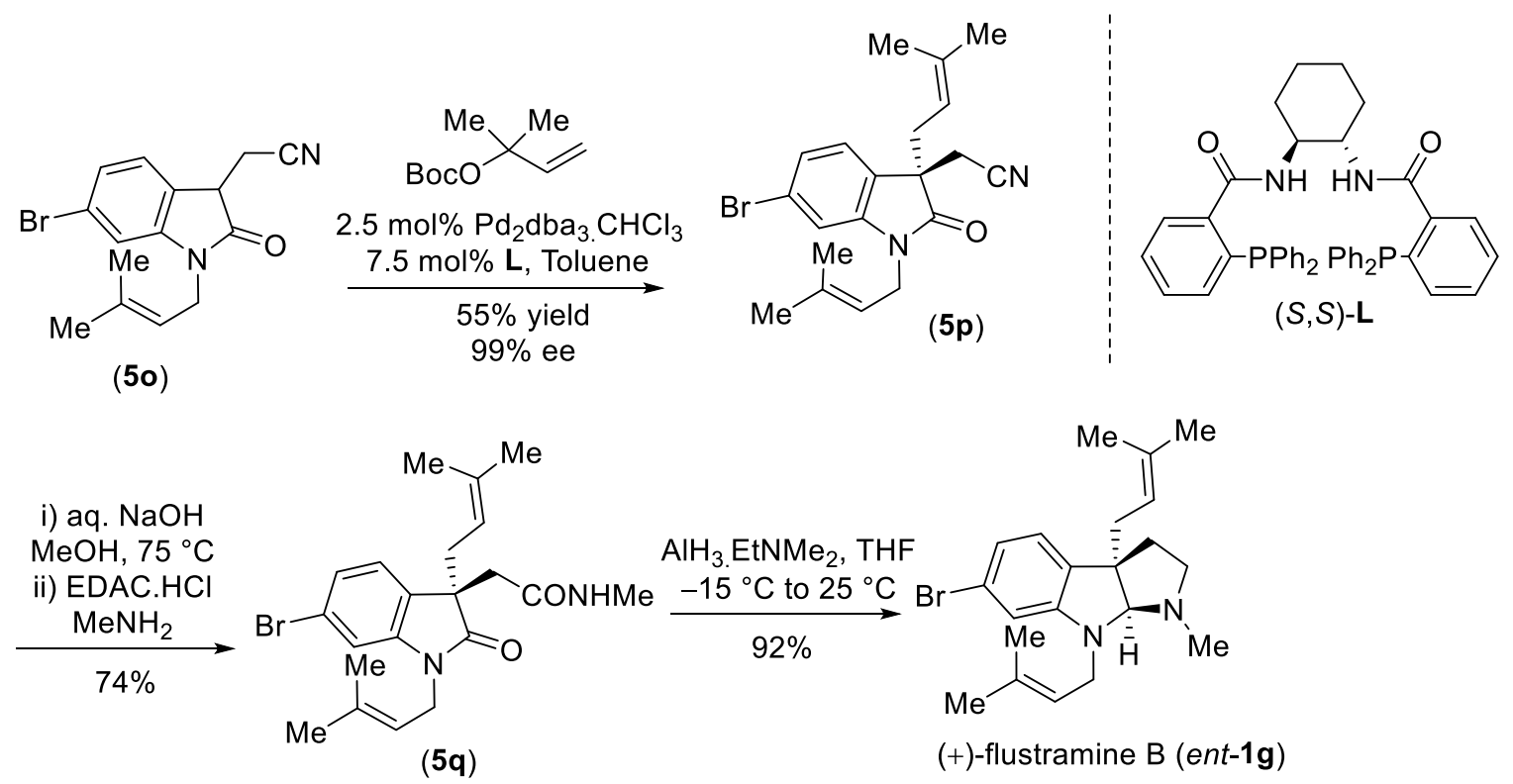

Scheme 26. Synthesis of (+)-flustramine B (ent-1g) by Trost et al.

In 2011, Trost and co-workers ${ }^{101}$ have demonstrated a palladium-catalyzed asymmetric prenylation of 2oxindoles via a $\pi$-prenyl organometallic species (Scheme 26). Compound 50 was treated with Boc protected reverse prenyl moiety in presence of $\mathrm{Pd}_{2} \mathrm{dba}_{3} \cdot \mathrm{CHCl}_{3}$ and ligand $\mathbf{L}$ under optimized condition to afford linear prenylated product $\mathbf{5 p}$ in $\mathbf{9 9 \%}$ ee. Later, hydrolysis of cyano group followed by amide formation furnished $\mathbf{5 q}$ in $74 \%$ yield, which was further treated with alane- $N, N$-dimethylethylamine complex to complete the total synthesis of (+)-flustramines B (ent-1g) (Scheme 26).

In 2012, Garg and co workers ${ }^{102}$ have developed a concise and practical synthesis of (+)-phenserine (ent1e), following an interrupted Fischer indolization (Scheme 27). Hemiaminal (23b) was reacted with $p$-methoxy phenyl hydrazine (23a) in $\mathrm{AcOH}$ medium to afford pyrrolidinoindoline (10h) in $78 \%$ yield. Reduction of carbamate $10 \mathrm{~h}$ by Red-Al afforded $( \pm$ )-esermethole (1c). Later, the treatment of $( \pm)$-esermethole (1c) with (-)di tolyl-L-tartaric acid in THF led to crystallization to furnish (+)-esermethole (ent-1c). Next, Krapcho demethylation of $(+)$-esermethole (ent-1c) and carbomylation yielded (+)-phenserine (ent-1e) in $74 \%$ over 2 steps (Scheme 27). 
<smiles>COc1ccc(N(C)N)cc1</smiles>

(23a)<smiles>CC1CCN(C(C)(C)C)C1O</smiles>

(23b)

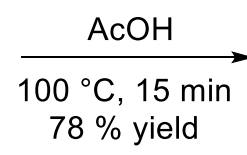

$78 \%$ yield

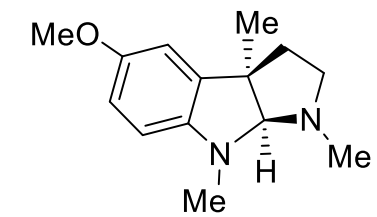

( \pm )-esermethole (1c) i) (-)-ditolyl-L-tartaric acid, THF ii) separation by crystallization

iii) $\mathrm{K}_{2} \mathrm{CO}_{3}, \mathrm{H}_{2} \mathrm{O}$ $33 \%$ yield, $94 \%$ ee (10h) Me<smiles>COc1ccc2c(c1)[C@@]1(C)CCN(C)[C@H]1N2C</smiles><smiles>COc1ccc2c(c1)[C@@]1(C)CCN(C)[C@]1(C)N2C</smiles><smiles>CN1CC[C@@]2(C)c3cc(O)ccc3N(C)[C@H]12</smiles>

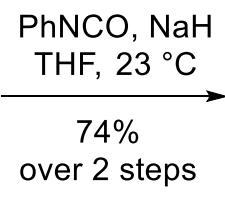

over 2 steps

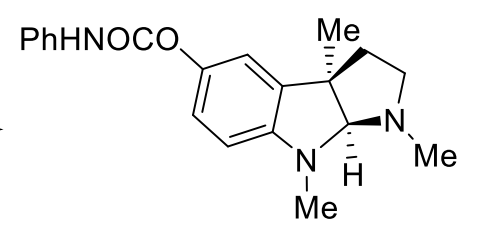

(+)-phenserine (ent-1e)

Scheme 27. Synthesis of (+)-esermethole (ent-1c), (+)-phenserine (ent-1e) following interrupted Fischer indolization by Garg et al.
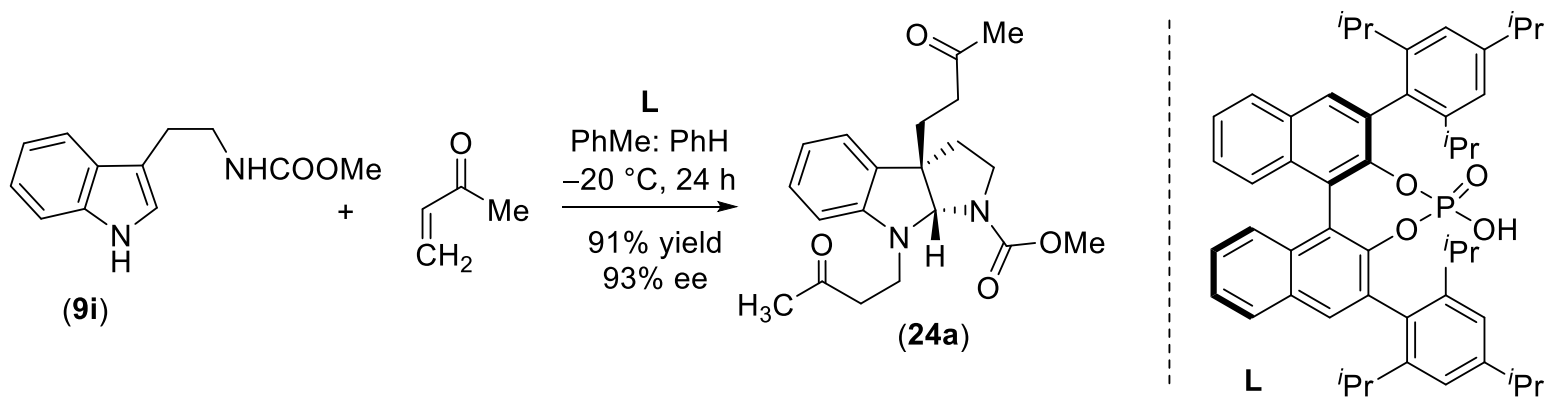

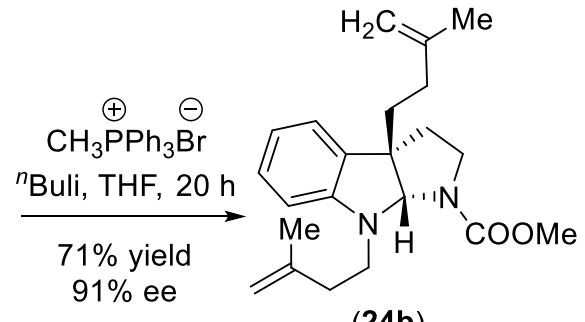

(24b)

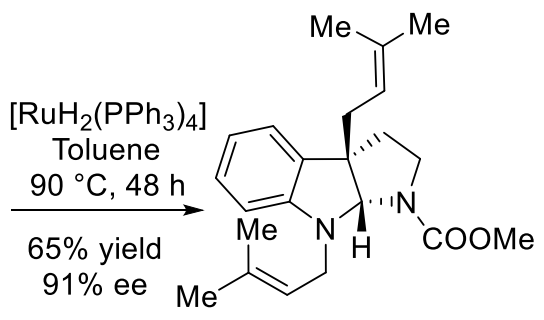

(24c)

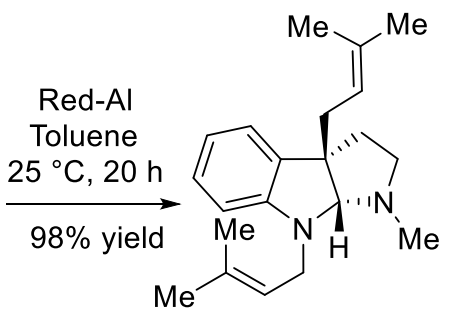

(-)-debromoflustramine B (1f)

Scheme 28. Chiral brønsted acids mediated synthesis of (-)-debromoflustramine (1f) by Antilla et al.

In 2012, Antilla and co-workers ${ }^{103}$ have disclosed chiral Brønsted acid, such as (R)-TRIP $(2,4,6-$ triisopropylphenyl binaphthyl phosphoric acid) catalyzed enantioselective formation of pyrroloindolines (Scheme 28). N-Moc tryptamine 9i was treated with methyl venyl ketone (MVK) in presence chiral Brønsted acid under standard condition to furnish enantioenriched $24 a$ in $91 \%$ yield with $93 \%$ ee. Later Wittig 
olefination of the chiral double Michael product, 24a produced high yield of 24b. A Ru-catalyzed isomerization of terminal olefin followed by reductive $N$-methylation completed the total synthesis of (-)debromoflustramine B (1f) (Scheme 28).

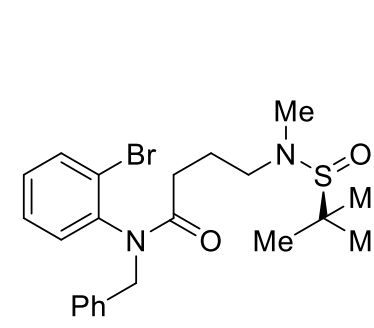

(25a)
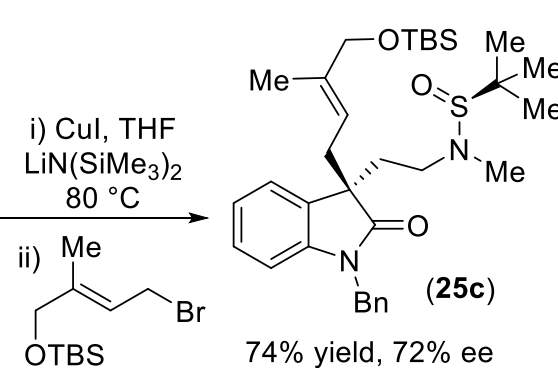

$74 \%$ yield, $72 \%$ ee

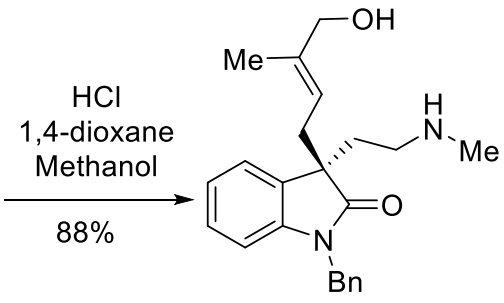

(25e)
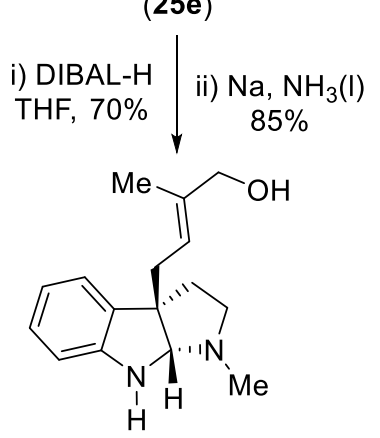

pseudophrynaminol (10)

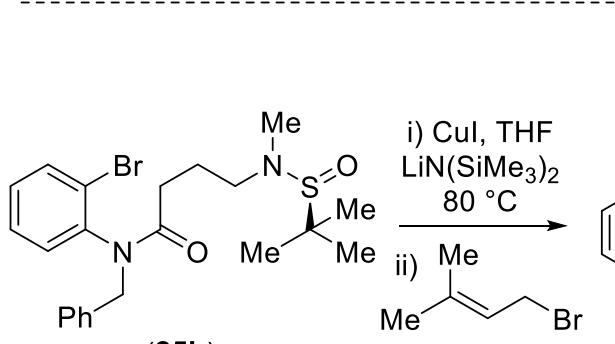

(25b)

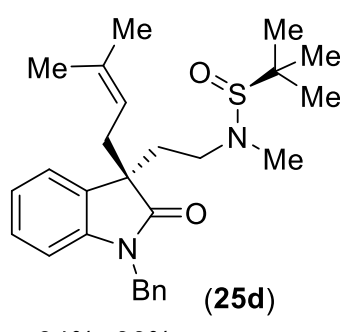

$84 \%, 66 \%$ ee

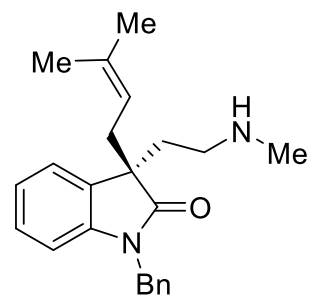

(25f)
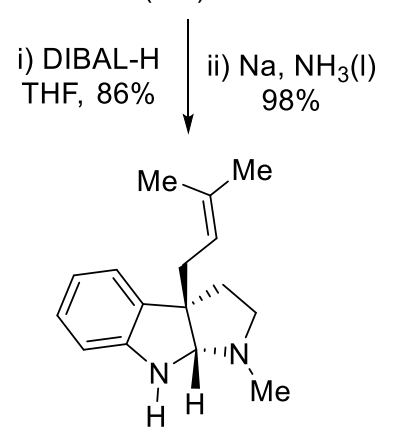

(-)-debromoflustramine $E(1 \mathrm{~h})$

Scheme 29. Copper catalyzed enantioselective synthesis of (-)-pseudophrynaminol (10) and (-)debromoflustramine $E$ (1h) by Zhang et al.

In 2012, Zhang et. al. have ${ }^{104}$ developed a stereocontrolled copper catalyzed Intramolecular alkylation of o-bromoanilides bearing a chiral sulfinyl amide unit to synthesize the precursors for the total synthesis of flustramine as well as pseudophrynamine alkaloids (Scheme 29). Next, in presence of different alkyl bromide copper mediated strategy completed the synthesis of targated molecules $\mathbf{2 5 c}$ and $\mathbf{2 5 d}$. Treatment of these key intermediates 25c and 25d with $\mathrm{HCl}$ and $\mathrm{MeOH}$ afforded amine compounds $\mathbf{2 5 e}$ and $\mathbf{2 5 f}$ with $88 \%$ and $85 \%$ 
yield, respectively (Scheme 29). Further, DIBAL-H reduction followed by benzyl group deprotection under Birch reduction provided pseudophrynaminol (10) and debromoflustramine E (1h) with $85 \%$ and $98 \%$ yield, respectively (Scheme 29).

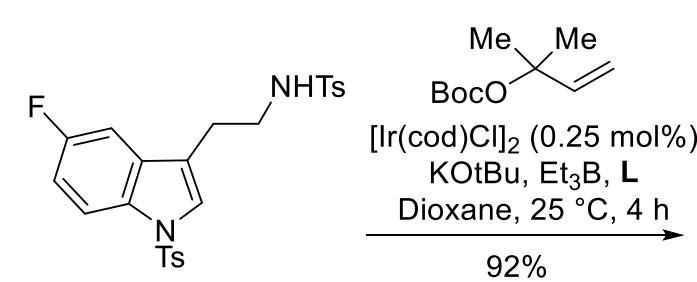

(9j)

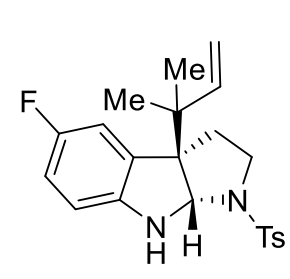

(24d)

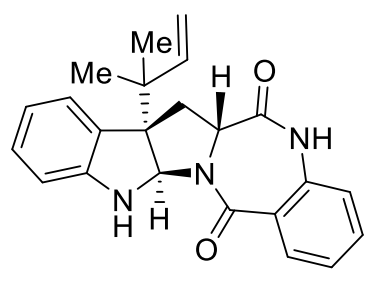

$(+)$-aszonalenin $(\mathbf{9 k})$

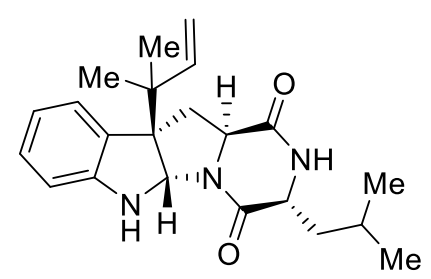

(-)-brevicompanine B (9I)

Scheme 30. Ir Catalyzed reverse Prenylated pyrroloindoline synthesis by Carreira et al.

In 2014, Carreira and co-workers ${ }^{105}$ have developed a direct C3 selective reverse prenylation of tryptamine derivative (9j). The methodology employs a readily accessible Ir-catalyst and a simple dimethyl allyl carbonate as precursor for the prenyl group with a variety of 3 -substituted- $1 H$-indoles as substrates, involving the formation of vicinal quaternary centers (Scheme 30). The diastereoselective reaction with tryptophan methyl ester enables access to a adaptable hexahydropyrrolo[2,3-b]indole intermediate, which they used as precursor for the stereoselective synthesis of (+)-aszonalenin (9k) and (-)-brevicompanine B (9l) (Scheme 30).

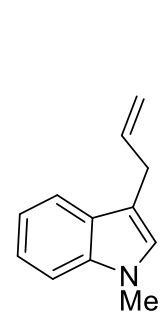

$(9 \mathrm{~m})$
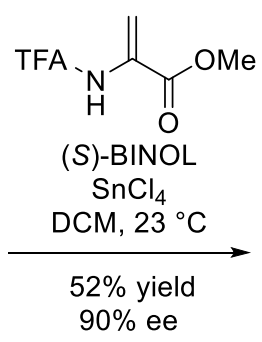

$19: 1 \mathrm{dr}$

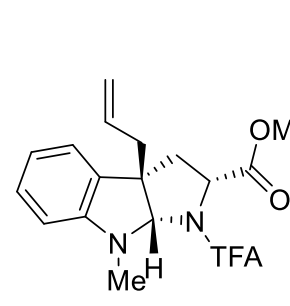

(24e)

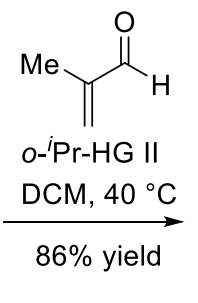

$\underset{86 \% \text { yield }}{\stackrel{\mathrm{DCM}}{\longrightarrow} 40{ }^{\circ} \mathrm{C}}$

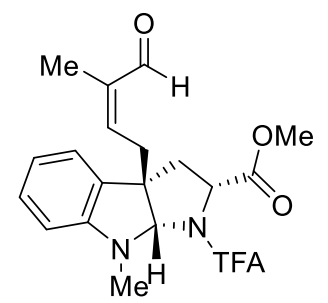

(24f)

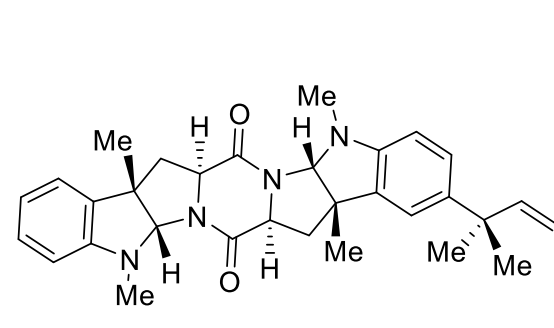

$(-)$-lansai B (9n)

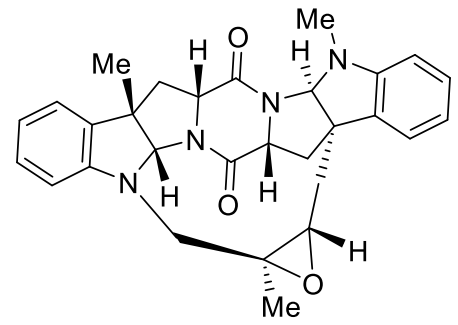

(+)-nocardioazine A (9o)

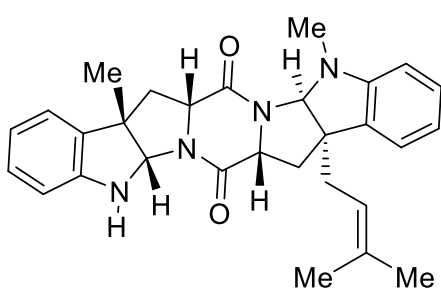

$(+)$-nocardioazine B (9p)

Scheme 31. Enantioselective pyrroloindoline synthesis by Reisman et al. 
In the same year, Reisman et. al. ${ }^{106}$ have reported enantioselective approach to pyrroloindolines from C3allylated indole $9 \mathrm{~m}$ and 2-amidoacrylates using $\mathrm{SnCl}_{4}-(R)-3,3$-dichloro-BINOL catalyst (Scheme 31). This strategy depends on a formal $(3+2)$ cycloaddition reaction. Follwing this methodology, they had successfully completed the total syntheses of (-)-lansai B (9n) and (+)- nocardioazines A (9o) and B (9p) (Scheme 31).

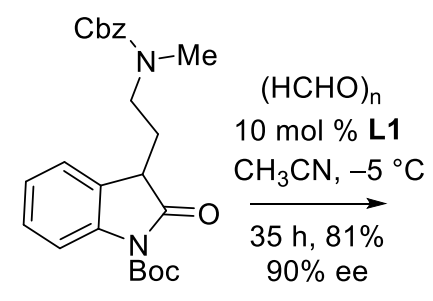

(26a)

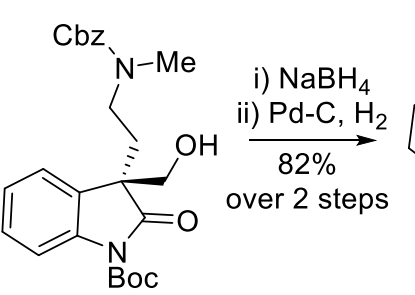

(26b)
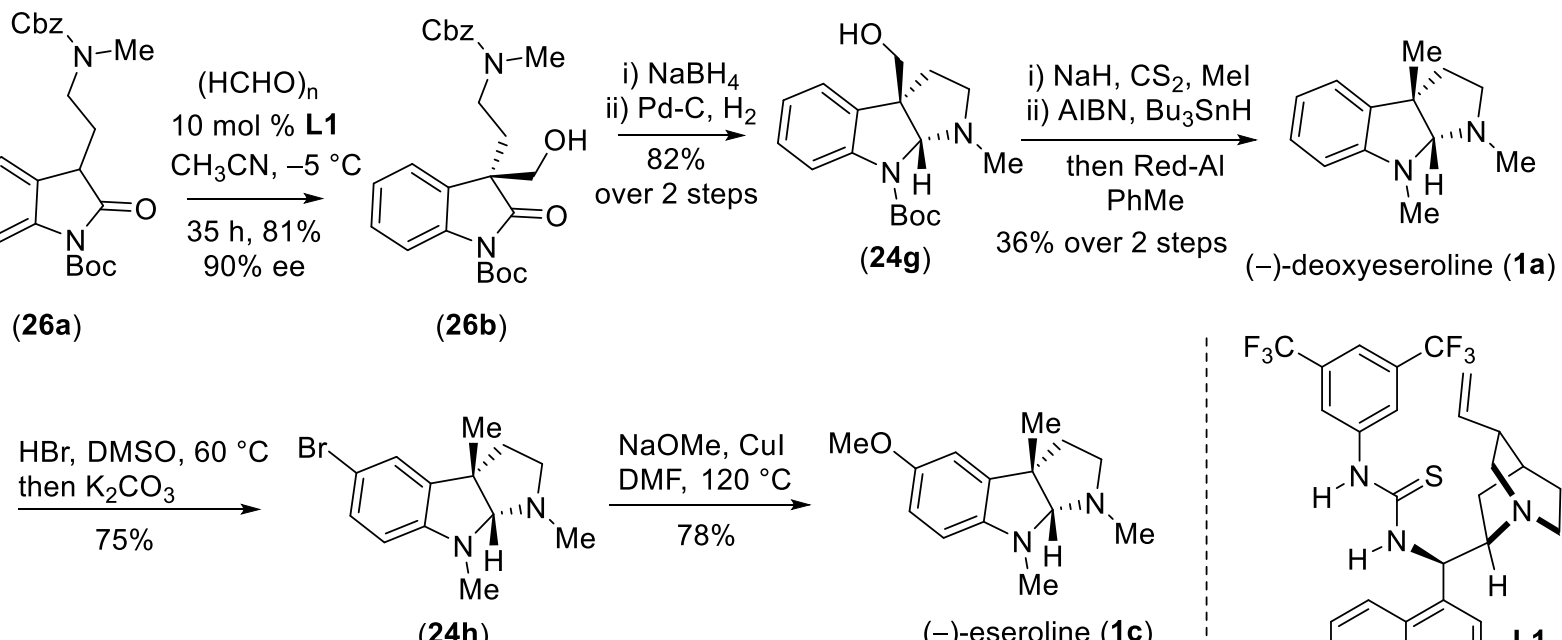

(24h)<smiles>C=CC1CN2CCC1CC2[C@H](NC(=S)Nc1cc(C(F)(F)F)cc(C(F)(F)F)c1)c1ccnc2ccccc12</smiles>

Scheme 32. Enatioselective organocatalytic syntheses of various pyrroloindoline alkaloids by Bisai et al.

In the year 2015, Bisai et. al. ${ }^{107}$ have developed enantioselective organocatalytic hydroxymethylation of 2oxindole 26a using paraformaldehyde as a C1 unit with $81 \%$ yield and $90 \%$ ee (Scheme 32 ). Starting from the enantioenriched compound $\mathbf{2 6 b}$, they carried out the total synthesis of $(-)$-deoxyeseroline (1a), (-)-eseroline (1b) and (-)-pseudophrynamine (1d). Compound $\mathbf{2 6 b}$ was treated with $\mathrm{NaBH}_{4}$ followed by pallidium catalyzed hydrogenolysis afforded hexahydropyrroloindoline core, which upon xanthate mediated reduction (with $n$ tributyl tin hydride in the presence of AIBN) alkaloid (-)-deoxyeseroline (1a).

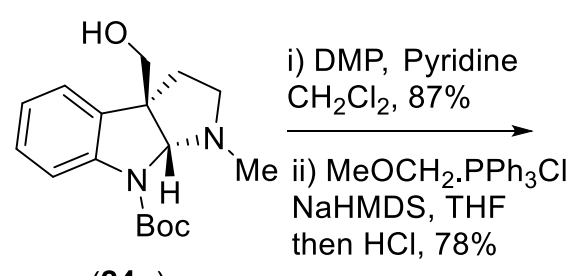

(24g)

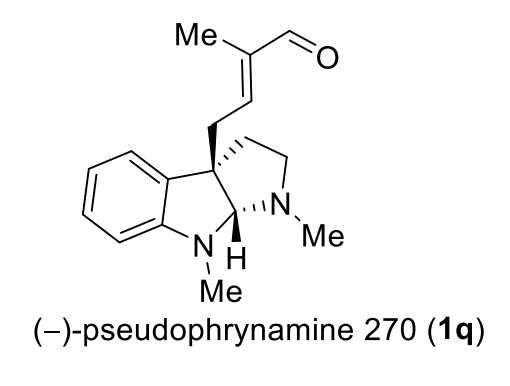

(-)-pseudophrynamine 270 (1q)

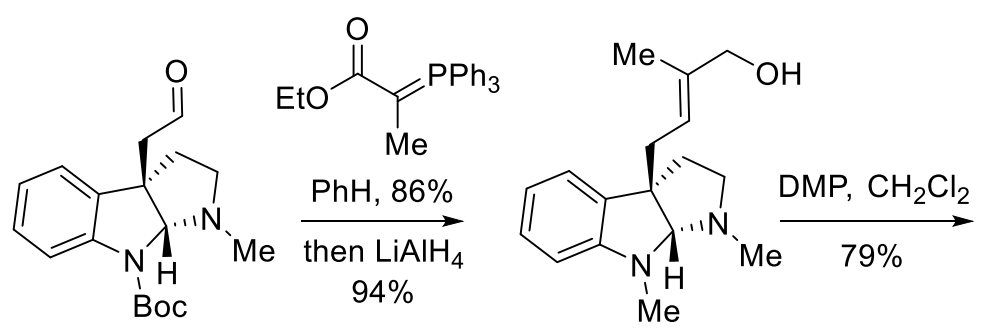

(26c)

$(-)$-pseudophrynamine 272A (1p)

Scheme 33. Total syntheses of C-prenylated pyrroloindoline alkaloids by Bisai et al. 
Further treatment with $\mathrm{HBr}$ and DMSO to afford C-5 brominated compound (24h) which was further reacted with NaOMe and Cul furnished the total synthesis of (-)-esermethole (1c) with 78\% yield. A further Dess-Martin periodinane (DMP) oxidation of compound (24g) followed by Witting homologation afforded aldehyde (26c). Next, a reaction with a stabilized Witting followed by $\mathrm{LiAlH}_{4}$ reduction furnished (-)pseudophrynamine $272 \mathrm{~A}(\mathbf{1 p})$. The latter on subsequent oxidation with DMP completed the first total synthesis of (-)-pseudophrynamine 270 (1q) (Schemes 32 and 33).

Recently, in 2018, You group ${ }^{108}$ have developed a palladium-catalyzed asymmetric dearomative prenylation of tryptamine derivatives $\mathbf{9 i}$ to afford $\mathbf{2 4 h}$ in $\mathbf{9 5 \%}$ ee (Scheme 34 ). With $\mathbf{2 4 h}$ in hand, concise total syntheses of (-)-flustramine B (19), (-)-debromoflustramine B (1g), (-)-pseudophrynaminol (10) were completed in few steps (Schemes 34).

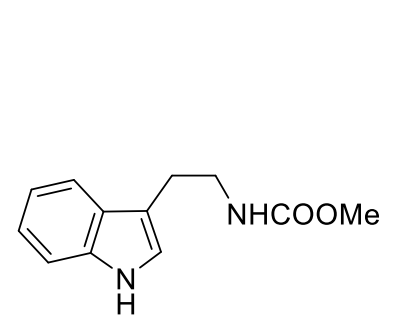

(9i)

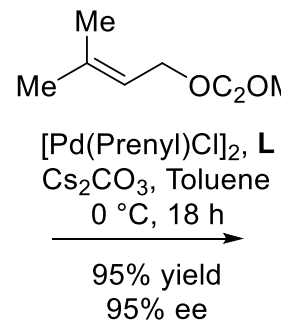

$95 \%$ ee
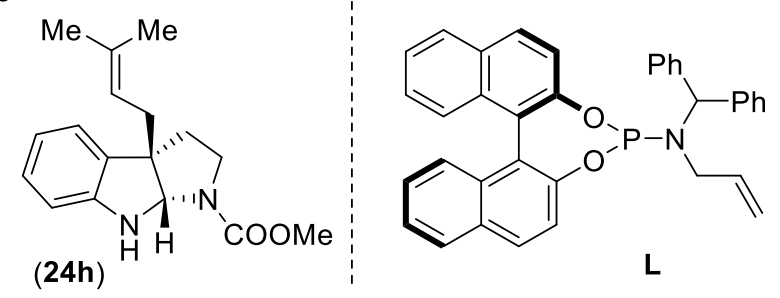

Scheme 34. Palladium-catalyzed asymmetric dearomative prenylation by You et al.

In 2019, Xu et. al. ${ }^{109}$ have reported the total synthesis of (-)-fructigenine A (1n) in a highly convergent and biomimetic fashion from the commercially available $(S)$-tryptophan. Starting from L-tryptaphone derivative, $\mathrm{AlCl}_{3}$ mediated one-pot diastereoselective Meerwein-Eschenmoser-Claisen (MEC) rearrangement was developed to construct C3 reverse prenylated oxindole $(\mathbf{2 7 c})$.

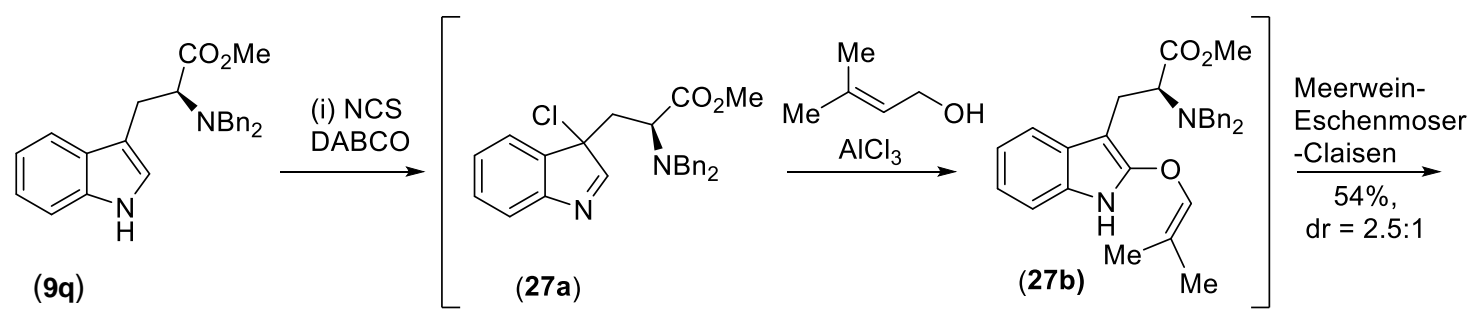

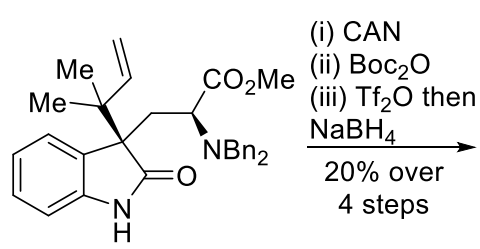

(27c)

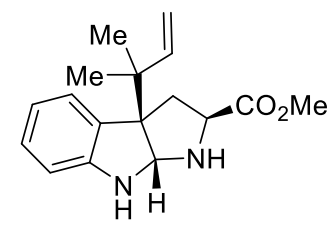

(27d)

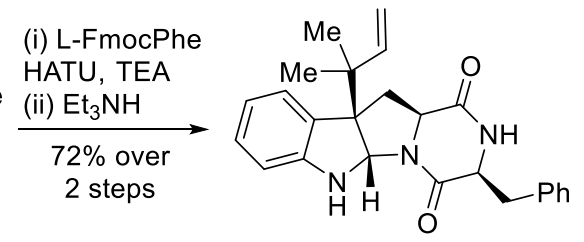

(27e)

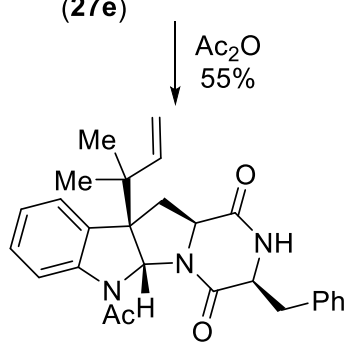

fructigenine $A(1 \mathbf{n})$

Scheme 35. Synthesis of (-)-fructigenine A (1n) by Xu et al. 
Compound $\mathbf{2 7 c}$ was converted to $\mathbf{2 7 d}$ in $\mathbf{2 0 \%}$ yield over 4 steps. Later, compound $\mathbf{2 7 d}$ was coupled with LFmoc-phenylalanine and cyclized upon Fmoc removal to synthesize diketopiparizine 27e. Finally, acetylation of compound 27e completed the total synthesis of (-)-fructigenine A (1n) (Schemes 35).

\section{Conclusions}

This review is intended to provide an overview of the complex hexahydropyrrolo[2,3- $b]$ indole alkaloids where biosynthetic relationship and synthetic approaches to this family of alkaloids have been discussed elaborately. The fascinating molecular architecture of the members of this natural product family has stimulated the interest of numerous synthetic chemists which has led to a number of creative synthetic approaches and beautiful total syntheses. Although, the biological activities of only a few numbers of hexahydropyrrolo[2,3$b]$ indole alkaloids are reported, the exhaustive biological potential of the majority of hexahydropyrrolo[2,3$b$ ]indole alkaloids has yet to be evaluated. The knowledge from biological stidues would be useful in screening these products for therapeutic applications.

\section{Acknowledgements}

AB sincerely thanks the SERB, DST, Govt. of INDIA [CRG/2019/000113], the Council of Scientific and Industrial Research (CSIR), Govt. of India [02(0295)/17/EMR-II], and Ministry of Earth Science (MoES), Govt. of India [MoES-2/DS/6/2007 PC-IV] for generous support. Facilities from IISER Bhopal and IISER Kolkata is gratefully acknowledged.

\section{References and Notes}

1. For review, see: Ruiz-Sanchis, P.; Savina, S. A.; Albericio, F.; Álvarez, M. Chem. - Eur. J. 2011, 17, 1388 and references cited.

https://doi.org/10.1002/chem.201001451

2. Sjoblom, T.; Bohlin, L.; Christophersen, C. Acta Pharm. Suec. 1983, 20, 415 and references therein.

PMID: 6675420

3. Takano, S.; Ogasawara, K. Alkaloids 1990, 36, 225.

https://doi.org/10.1016/S0099-9598(08)60084-X

4. Brossi, A. J. Med. Chem. 1990, 33, 2311.

https://doi.org/10.1021/jm00171a001

5. Jobst, J.; Hesse, O. Ann. Chem. Pharm. 1864, 129, 115.

6. Triggle, D. J.; Mitchell, J. M.; Filler, R. CNS Drug Reviews 1998, 4, 87. https://onlinelibrary.wiley.com/doi/pdf/10.1111/j.1527-3458.1998.tb00059.x

7. Stedman, E.; Barger, G. J. Chem. Soc., Trans., 1925, 127, 247.

https://doi.org/10.1039/CT9252700247

8. Furst, S.; Friedmann, T.; Bartolini, A.; Bartolini, R.; Aiello-Malmberg, P.; Galli, A.; Somogyl, G. T.; Knoll, J. Eur. J. Pharmacol., 1982, 83, 233. 
9. Peters, L.; König, G. M.; Terlau, H.; Wright, A. D. J. Nat. Prod. 2002, 65, 1633. https://doi.org/10.1021/np0105984

10. Rochfort, S. J.; Moore, S.; Craft, C.; Martin, N. H.; Van Wagoner, R. M.; Wright, J. L. C. J. Nat. Prod. 2009, $72,1773$.

https://doi.org/10.1021/np900282i

11. Karwowski, J. P.; Jackson, M.; Rasmussen, R. R.; Humphrey, P. E.; Poddig, J. B.; Kohl, W. L.; Scherr, M. H.; Kadam, S.; McAlpine, J. B. J. Antibiot. 1993, 46, 374.

https://doi.org/10.7164/antibiotics.46.374

12. Hochlowski, J. E.; Mullally, M. M.; Spanton, S. G.; Whittern, D. N.; Hill, P.; McAlpine, J. B. J. Antibiot. 1993, 46, 380.

https://doi.org/10.7164/antibiotics.46.380

13. Arai, K.; Kimura, K.; Mushiroda, T.; Yamamoto, Y. Chem. Pharm. Bull. 1989, 37, 2937. https://doi.org/10.1248/cpb.37.2937

14. Spande, T. F.; Edwards, M. W.; Pannell, L. K.; Daly, J. W. J. Org. Chem. 1988, 53, 1222. https://doi.org/10.1021/jo00241a019

15. Daly, J. W.; Garraffo, H. M.; Pannell, L. K.; Spande, T. F. J. Nat. Prod. 1990, 53, 407. https://doi.org/10.1021/np50068a020

16. Saxton, J. E. Nat. Prod. Rep. 1991, 8, 251. https://doi.org/10.1039/NP9910800251

17. Smith, B. P.; Tyler, M. J.; Kaneko, T.; Garraffo, H. M.; Spande, T. F.; Daly, J. W. J. Nat. Prod. 2002, 65, 439. https://doi.org/10.1021/np010506a

18. Christophersen, C. Acta Chem. Scand. B, 1985, 39, 517. http://actachemscand.org/pdf/acta vol 39b p0517-0529.pdf

19. Peters, L.; Wright, A. D.; Krick, A.; Koenig, G. M. J. Chem. Ecol. 2004, 30, 1165. https://doi.org/10.1023/B:JOEC.0000030270.65594.f4

20. Julian, P. L, Pikl, J. J. Am. Chem. Soc. 1935, 57, 755. https://doi.org/10.1021/ja01307a051

21. Butler, A.; Walker, J. V. Chem. Rev., 1993, 93, 1937. https://doi.org/10.1021/cr00021a014

22. Gribble, G. W. Chem. Soc. Rev., 1999, 28, 335. https://doi.org/10.1039/A900201D

23. Carle, J. S, Christophersen, C. J. Am. Chem. Soc. 1979, 101, 4012. https://doi.org/10.1021/ja00508a073

24. Carle, J. S.; Christophersen, C. J. Org. Chem., 1981, 46, 3440. https://doi.org/10.1021/jo00330a011

25. Holst, P. B.; Anthoni, U.; Christophersen, C.; Nielsen, P. H. J. Nat. Prod. 1994, 57, 997. https://doi.org/10.1021/np50109a020

26. Smith, B. P.; Tyler, M. J.; Kaneko, T.; Garraffo, H. M.; Spande, T. F.; Daly, J. W. J. Nat. Prod. 2002, 65, 439. https://doi.org/10.1021/np010506a

27. Morales-Ríosa, M. S.; Suárez-Castillo, O. R. Nat. Prod. Commun. 2008, 3, 629. https://doi.org/10.1177/1934578X0800300421

28. Laycock, M. V.; Wright, J. L. C.; Findlay, J. A.; Patil, A. D. Can. J. Chem., 1986, 64, 1312. https://doi.org/10.1139/v86-218

29. Christoffers, J.; Mann, A. Angew. Chem., Int. Ed. 2001, 40, 4591. 
https://doi.org/10.1002/1521-3773(20011217)40:24<4591::AID-ANIE4591>3.0.CO;2-V

30. Douglas, C. J.; Overman, L. E. Proc. Natl. Acad. Sci. USA 2004, 101, 5363.

https://doi.org/10.1073/pnas.0307113101

31. Bruncko, M.; Crich, D.; Samy, R. J. Org. Chem. 1994, 59, 5543.

https://doi.org/10.1021/jo00098a011

32. Cardoso, A. S.; Srinivasan, N.; Lobo, A. M.; Prabhakar, S. Tetrahedron Lett. 2001, 42, 6663. https://doi.org/10.1016/S0040-4039(01)01359-4

33. Austin, J. F.; Kim, S-G.; Sinz, C. J.; Xiao, W-J.; MacMillan, D. W. C. Proc. Natl. Acad. Sci. USA 2004, 101, 5482.

https://doi.org/10.1073/pnas.0308177101

34. Lysek, N.; Rachor, E.; Lindel, T.; Z. Naturforsch.C. 2002, 57C, 1056.

https://doi.org/10.1515/znc-2002-11-1218

35. Peters, L.; Wright, A. D.; Kehraus, S.; Guendisch, D.; Tilotta, M. C.; Koenig. G. M. Planta Medica, 2004, 70, 883.

https://doi.org/10.1055/s-2004-832610

36. Holmstedt, B. The ordeal bean of old calabar: The pageant of Physostigma venenosum in medicine. In: Swain T, ed. Plants In the development of modern medicine. Cambridge, MA, 1972, 303.

37. Somani, S. M.; Dube, S. N. Int. J. Clin. Pharmacol. Therap. Toxicol. 1989, 27, 367.

https://europepmc.org/article/med/2676871

38. Triggle, D. J.; Mitchell, J. M.; Filler, R. CNS Drug Reviews 1998, 4, 87.

https://doi.org/10.1111/j.1527-3458.1998.tb00059.x

39. Dragstedt, C. A. Trial by ordeal. Q. Bull. Northwest. Univ. School. Med. 1945, 19, 137. PMCID: PMC3802583

40. Robertson, D. A. Edinburgh Med. J. 1863, 8, 815.

PMCID: PMC5277160

41. Kronfeld, P. C. Survey Ophthalmol. 1970, 14, 479.

PMID: 4911115

42. Nickalls, R. W. D.; Nickalls, E. A. Anaesthesia 1988, 43, 776.

https://doi.org/10.1111/j.1365-2044.1988.tb05755.x

43. Walker, M. B. The Lancet 1934, 1, 1200.

https://doi.org/10.1016/S0140-6736(00)94294-6

44. Koster, R. J. Pharmacol. Exp. Ther. 1946, 88, 39.

http://ipet.aspetjournals.org/content/88/1/39

45. Somani, S. M.; Dube, S. N. Int J. Clin. Pharmacol. Ther. Toxicol. 1989, 27, 367.

PMID: 2676871

46. Deutsch, J. A. Science 1971, 174, 788.

http://doi.org/10.1126/science.174.4011.788

47. Deutsch, J. A. New York: Academic Press, 1983, 367.

48. Bartus, R. T.; Dean, R. L. Science 1997, 217, 405.

http://doi.org/10.1126/science.7046051

49. Coyle, J. T.; Price, D. L.; DeLong, M. R. Science 1983, 219, 1184.

http://doi.org/10.1126/science.6338589

50. Murray, A.; Cottrell, D. F.; Woodman, M. P. Vet. Res. Commun. 1994, 18, 199.

https://link.springer.com/content/pdf/10.1007/BF01839269.pdf 
51. Bartolini, R.; Aiello-Malmberg, P.; Bartolini, A.; Galli, A.; Renzi, G. 7th Int. Congr. Pharmacology. Paris, 1978, Jul. 16-21, abstr. 430.

52. B. Robinson. J. Pharm. Pharmacol., 1965, 17, 89. https://doi.org/10.1111/j.2042-7158.1965.tb07619.x

53. Flodmark, S.; Wramner, T. Acta Physiol. Scand. 1945, 9, 88. https://doi.org/10.1111/i.1748-1716.1945.tb03087.x

54. Hendershot, L. C.; Forsaith, J. J. Pharmacol. Exp. Ther. 1959, 125, 237.

PMID: 13642264

55. Harris, L. S.; Dewey, W. L.; Howes, J. F.; Kennedy, J. S.; Pars, H. J. Pharmacol. Exp. Ther. 1969, $169,17$. PMID: 4389919

56. Pleuvry, B. J.; Tobias, M. A. Br. J. Pharmacol. 1971, 43, 706. https://doi.org/10.1111/i.1476-5381.1971.tb07205.x

57. Ellis, S.; Krayer, O.; Plachte, F. L. J. Pharmacol. Exp. Ther. 1943, 79, 309. http://ipet.aspetjournals.org/content/79/4/309

58. Galli, A.; Renzi, G.; Bartolini, A.; Bartolini, R.; Malmberg, P. J. Pharm. Pharmacol., 1979, $31,784$. https://doi.org/10.1111/i.2042-7158.1979.tb13660.x

59. Ireson, J. D. Br. J. Pharmacol. 1970, 40, 92. http://doi.org/10.1111/j.1476-5381.1970.tb10614.x

60. Greig, N. H.; Micheli, E. D.; Holloway, H. W.; Yu, Q.-S.; Utsuki, T. T.; Perry, A.; Brossi, A.; Ingram, D.; Deutsch, K. J.; Lahiri, D. K.; Soncrant, T. T. Acta. Neurol. Scand. 2000, 176, 74.

https://doi.org/10.1034/j.1600-0404.2000.00311.x

61. Greig, N. H.; Sambamurti, K.; Yu, Q-S.; Brossi, A.; Bruinsma, G. B.; Lahiri, D. K. Current Alzheimer Research, 2005, 2, 281.

https://doi.org/10.2174/1567205054367829

62. Becerril, E. R.; Nathan, P. J.; Alvarez, V. M. P.; Rios, M. S. M. J. Med. Chem. 2008, 51, 5271.

https://doi.org/10.1021/jm800277g

63. Hodgson, J. W.; Mitchell, M. O.; Thomas, M. L.; Waters, K. F.; Powell, D. Bioorg. Med. Chem. Lett. 1995, 5, 2527.

https://doi.org/10.1016/0960-894X(95)00443-W

64. Dix, A. V.; Meseck, C. M.; Lowe, A. J.; Mitchell, M. O. Bioorg. Med. Chem. Lett. 2006, 16, 2522. https://doi.org/10.1016/j.bmcl.2006.01.093

65. Spande, T. F.; Edwards, M. W.; Pannell, L. K.; Daly, J. W. J. Org. Chem. 1988, 53, 1222. https://doi.org/10.1021/jo00241a019

66. Badio, B.; Garraffo, H. M.; Padgett, W. L.; Greig, N. H.; Daly, J. W. Biochem. Pharmacol. 1997, 53, 671. https://doi.org/10.1016/S0006-2952(96)00878-7

67. For naturally occurring MDR reversal agent see: Stratman, K.; Burgoyne, D.; Moore, R. E.; Patterson, G. M. L.; Smith, C. D. J. Org. Chem. 1994, 59, 7219.

https://doi.org/10.1021/jo00103a011

68. Muhtadi, F. J.; El-Hawary, S. S. Analytical Profiles of Drug Substances 1990, 18, 289. https://doi.org/10.1016/S0099-5428(08)60675-9

69. Peters, L.; König, G. M.; Terlau, H.; Wright, A. D. J. Nat. Prod. 2002, 65, 1633. https://doi.org/10.1021/np0105984

70. Rochfort, S. J.; Moore, S.; Craft, C.; Martin, N. H.; Van Wagoner, R. M.; Wright, J. L. C. J. Nat. Prod. 2009, $72,1773$. 
https://doi.org/10.1021/np900282i

71. Julian, P. L.; Pikl, J. J. Am. Chem. Soc. 1935, 57, 755.

https://doi.org/10.1021/ja01307a051

72. Polonovski, M.; Nitzberg, C. Bull. Soc. Chim. Fr., [iv] 1916, 19, 33.

73. Harley-Mason, J.; Jackson, A. H. J. Chem. Soc. 1954, 3651.

https://doi.org/10.1039/JR9540003651

74. Ikeda, M.; Matsugashita, S.; Tamura, Y. J. Chem. Soc., Perkin Trans. 1. 1977, 1770.

https://doi.org/10.1039/P19770001770

75. Hino, T.; Tanaka, T.; Matsuki, K.; Nakagawa, M. Chem. Pharma. Bull. 1983, 31, 1806.

https://doi.org/10.1248/cpb.31.1806

76. Taniguchi, M.; Hino, T. Synthesis of cyclic tautomers of tryptophans and tryptamines. Tetrahedron 1981, $37,1487$.

https://doi.org/10.1016/S0040-4020(01)92088-5

77. Shishido, K.; Shitara, E.; Komatsu, H.; Hiroya, K.; Fukumoto, K.; Kametani, T. J. Org. Chem. 1986, 51 , 3007. https://doi.org/10.1021/jo00365a029

78. Takano, S.; Goto, E.; Hirama, M.; Ogasawara, K. Chem. Pharm. Bull. 1982, 30, 2641.

https://doi.org/10.1248/cpb.30.2641

79. Jensen, J.; Anthoni, U.; Christophersen, C.; Nielsen, P. H. Acta Chem. Scand. 1995, 49, 68.

http://doi.org/10.3891/acta.chem.scand.49-0068

80. Somei, M.; Yamada, F.; Izumi, T.; Nakajou, M. Heterocycles 1997, 45, 2327.

http://doi.org/10.3987/COM-97-7989

81. Morales-Ríos, M. S.; Sua'rez-Castillo, O. R.; Joseph-Nathan, P. J. Org. Chem. 1999, 64, 1086. https://doi.org/10.1021/jo982090k

82. Tan, G. H.; Zhu, X.; Ganesan, A. Org. Lett. 2003, Vol. 5, No. 10, 1801.

https://doi.org/10.1021/ol034516+

83. López-Alvarado, P.; Caballero, E.; Avendano, C.; Menéndez, J. C. Org. Lett. 2006, 8, 4303. https://doi.org/10.1021/ol061631m

84. Dix, A. V.; Meseck, C. M.; Lowe, A. J.; Mitchell, M. O. Bioorg. Med. Chem. Lett. 2006, 16, 2522. https://doi.org/10.1016/j.bmcl.2006.01.093

85. Miyamoto, H.; Okawa, Y.; Nakazaki, A.; Kobayashi S. Tetrahedron Lett. 2007, 48, 1805. https://doi.org/10.1016/j.tetlet.2007.01.002

86. Lin, A.; Yang, J.; Hashim, M. Org. Lett. 2013, 15, 1950.

https://doi.org/10.1021/ol4005992

87. Zhou, B.; Hou, W.; Yang, Y.; Feng, H.; Li, Y. Org. Lett. 2014, 16, 1322.

https://doi.org/10.1021/ol500033w

88. Liu, C.; Yin, Q.; Dai, L-X.; You, S-L. Chem. Commun. 2015, 51, 5971.

http://doi.org/10.1039/C5CC00780A

89. Yi, J-C.; Liu, C.; Dai, L-X.; You, S-L. Chem. Asian J. 2017, 12, 2975.

http://doi.org/10.1002/asia.201701151

90. Kumar, N.; Gavit, V. R. Maity, A.; Bisai, A. J. Org. Chem. 2018, 83, 10709.

https://doi.org/10.1021/acs.joc.8b01101

91. Roy, A.; Maity, A.; Giri, R.; Bisai, A. Asian J. Org. Chem. 2020, 9, 226. https://doi.org/10.1002/ajoc.202000027

92. Lee, T. B. K.; Wong, G. S. K. J. Org. Chem. 1991, 56, 872. 
https://doi.org/10.1021/jo00002a074

93. Marsden, S. P.; Depew, K. M.; Danishefsky, S. J. J. Am. Chem. Soc. 1994, 116, 11143 https://doi.org/10.1021/ja00103a034

94. Matsuura, T.; Overman, L. E.; Poon, D. J. J. Am. Chem. Soc. 1998, 120, 6500. https://doi.org/10.1021/ja980788+

95. Austin, J. F.; Kim, S. G.; Sinz, C. J.; Xiao, W. J.; MacMillan, D. W. C. Proc. Natl. Acad. Sci. U.S.A. 2004, 101, 5482.

https://doi.org/10.1073/pnas.0308177101

96. Quancard, J.; Trost, B. M. J. Am. Chem. Soc. 2006, 128, 6314. https://doi.org/10.1021/ja0608139

97. Nakao, Y.; Ebata, S.; Yada, A.; Hiyama, T.; Ikawa, M.; Ogoshi, S. J. Am. Chem. Soc. 2008, 130, 12874. https://doi.org/10.1021/ja805088r

98. Bui, T.; Syed, S.; Barbas III C. F. J. Am. Chem. Soc. 2009, 131, 8758. https://doi.org/10.1021/ja903520c

99. Takiguchi, S.; lizuka, T. Kumakura, Y-S.; Murasaki, K.; Ban, N.; Higuchi, K.; Kawasaki, T.; J. Org. Chem. 2010, 75, 1126.

https://doi.org/10.1021/jo9023107

100. Trost, B. M.; Zhang, Y.; Chem. Eur. J. 2011, 17, 2916. https://doi.org/10.1002/chem.201002569

101. Trost, B. M.; Malhotra, S.; Chan, W. H. J. Am. Chem. Soc. 2011, 133, 7328. https://doi.org/10.1021/ja2020873

102. Schammel, A. W.; Chiou, G.; Garg, N. K. J. Org. Chem. 2012, 77, 725. https://doi.org/10.1021/jo202078z

103. Zhang, Z.; Antilla, J. C. Angew. Chem., Int. Ed. 2012, 51, 11778. https://doi.org/10.1002/anie.201203553

104. Zhou, Y.; Xi, Y.; Zhao, J.; Sheng, X.; Zhang, S.; Zhang, H. Org. Lett. 2012, 14, 3116. https://doi.org/10.1021/ol3012056

105. Ruchti, J.; Carreira, E. M. J. Am. Chem. Soc. 2014, 136, 16756. https://doi.org/10.1021/ja509893s

106. Wang, H.; Reisman, S. E. Angew. Chem., Int. Ed. 2014, 53, 6206. https://doi.org/10.1002/anie.201402571

107. De, S.; Das, M. K.; Bhunia, S.; Bisai, A. Org. Lett. 2015, 17, 5922. https://doi.org/10.1021/acs.orglett.5b03082

108. Tu, H. F.; Zhang, X.; Zheng, C.; Zhu, M.; You, S. L. Nat. Catal. 2018, 1, 601. https://doi.org/10.1038/s41929-018-0111-8

109. Yu, H.; Zong, Y.; Xu, T. Chem. Sci. 2020, 11, 656. http://doi.org/10.1039/C9SC05252F 


\section{Author's Biographies}

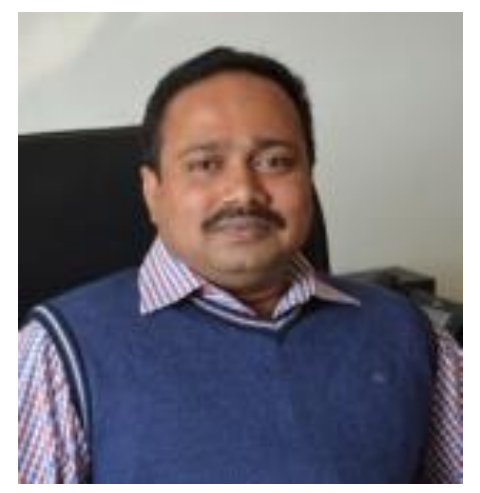

Alakesh Bisai received his M.Sc. degree in Organic Chemistry from Banaras Hindu University and obtained Ph.D. in synthetic Organic Chemistry under the supervision of Professor Vinod K. Singh from the Department of Chemistry, Indian Institute of Technology Kanpur in Sept. 2006. Immediately afterward, he moved to the College of Chemistry, University of California at Berkeley, where he held postdoctoral position in the research group of Professor Richmond Sarpong. During his stay at Berkeley, he completed concise total synthesis of 'lycopodium alkaloids' lyconadin A which received considerable attention from the synthetic community. During his Postdoctoral research, he received the GRC (Gordon Research Conference) award to Post-docs by Chair, $17^{\text {th }}$ GRC on Stereochemistry (2008), RI. In Dec. 2009, he left Berkeley and joined the Department of Chemistry, IISER Bhopal as an Assistant Professor. In Nov. 2013, he was appointed as an Associate Professor in the Department Chemistry. The research focus of the $A B$ research group includes the total synthesis of architecturally interesting biologically active natural products that provide an ideal platform for the invention of new strategies and highly selective organic transformations. A number of naturally occurring architecturally intriguing biological relevant secondary metabolites sharing all-carbon quaternary stereocenters have been synthesized by his research group at IISER Bhopal. He is the recipient of Young Scientist Award by the CRSI (2018), Research Grant for Young Scientist by the DST (2011) and the BRNS, DAE (2011). Since January, 2018, he has been working as a Professor of Chemistry at IISER Bhopal. In May, 2019, he moved to IISER Kolkata and setting up his new reasearch laboratory on Natural Product Synthesis. He has been awarded the prestigious 'CRSI Bonze Medal' for the year 2021 in recognition of his contributions in Chemical Sciences.

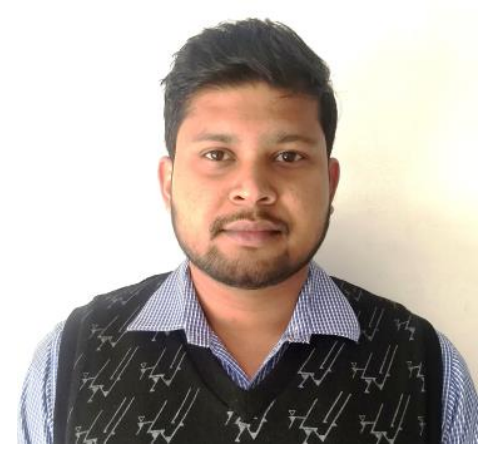

Avishek Roy was born in Midnapore, India on July 20, 1992. He completed his Bachelors in Chemistry (Hons.) from Garhbeta College, Vidyasagar University in 2012 and Masters in Chemistry from Vidyasagar University in 2014. He has received prestigious GATE and direct CSIR-SRF fellowships from the Govt. of India. Very recently he completed his Ph.D. in Organic Chemistry entitled as "Asymmetric Approaches to Hetero Dimeric 
Pyrroloindoline Alkaloids, Chimonanthidine and Calycanthidine" under the supervision of Prof. Alakesh Bisai from IISER Bhopal, India in 2020.

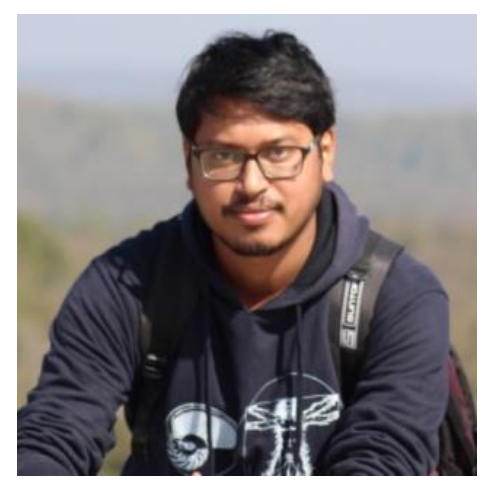

Arindam Maity was born in 1994 at Purba Medinipur, West Bengal, India. He graduated from Midnapore College in 2014 and completed his Master of Science (M.Sc.) in Chemistry from Vidyasagar University, India in 2016. He is presently pursuing his Ph.D degree in the field of Organic Total Synthesis at Indian Institute of Science Education and Research, Bhopal under the supervision of Prof. Alakesh Bisai. He is currently working on "Asymmetric Total Synthesis of Hexahydropyrrolo[2,3-b]indole Alkaloids".

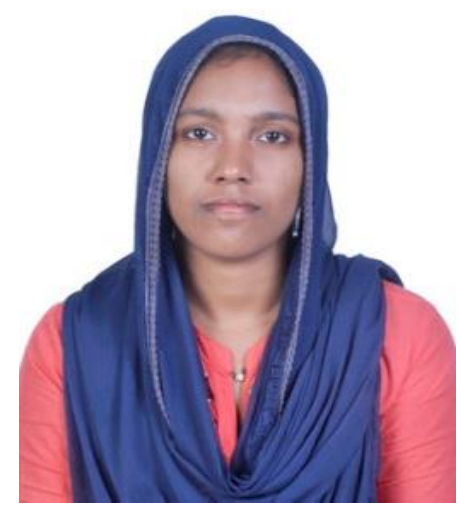

Saina Shaheeda M K completed her Bachelors in Science and Masters of Science in Chemistry (BS-MS dual degree) in 2017 from the Indian Institute of Science Education and Research Bhopal (IISER Bhopal). She is the recipient of the prestigious Inspire fellowship from the Govt. of India. During her BSMS dual degree program, Saina had completed her MS thesis in 'AB Research Group' at IISER Bhopal. Currently, she is continuing her Ph.D. in same group in total synthesis of naturally occurring alkaloids and working on "Asymmetric Total Synthesis of Hexahydropyrrolo[2,3-b]indole Alkaloids".

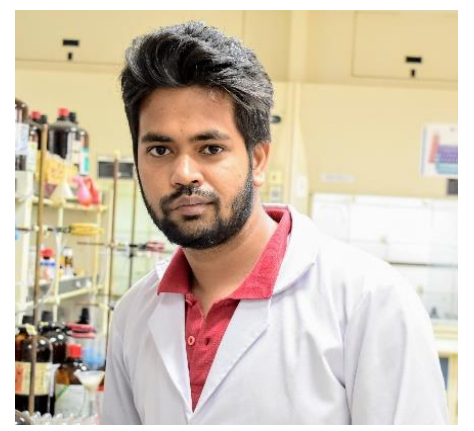


Rahul Giri was born on January 04, 1996 in Hazaribag, Jharkhand, India. After completing his elementary schooling from Kendriya Vidyalaya BSF Meru Hazaribag in 2013, he decided to move to Acharya Narendra Dev College (ANDC), University of Delhi where he received his Bachlor of Science (Honours) in Chemistry in 2016. Subsequently, he moved to the IISER BHOPAL in 2017 for his Integrated-PhD studies in AB Research Group with Prof. Alakesh Bisai. His current research focus is on "Total synthesis of hexahydropyrrolo[2,3-b]indole alkaloids of biological relevance". 